Article

\title{
Experimental Study of High-Strength Concrete-Steel Plate Composite Shear Walls
}

\author{
Dongqi Jiang ${ }^{1, *(\mathbb{D}}$, Congzhen Xiao ${ }^{2} \mathbb{D}$, Tao Chen ${ }^{2}$ and Yuye Zhang ${ }^{1} \mathbb{D}$ \\ 1 Department of Civil Engineering, School of Science, Nanjing University of Science and Technology, \\ Nanjing 210094, China \\ 2 Structural Institute, China Academy of Building Research, Beijing 100013, China \\ * Correspondence: jiangdongqi@njust.edu.cn; Tel.: +86-25-84315773
}

Received: 17 June 2019; Accepted: 8 July 2019; Published: 15 July 2019

\begin{abstract}
Shear walls are effective lateral load resisting elements in high-rise buildings. This paper presents an experimental study of the seismic performance of a composite shear wall system that consists of high-strength concrete walls with the embedded steel plate. Two sets of wall specimens with different aspect ratios (height/width, 1.5 and 2.7) were constructed and tested under quasi-static reversed cyclic loading, including five reinforced concrete shear walls (RCSW) and six reinforced concrete-steel plate shear walls (RCSPSW). The progression of damage, failure modes, and load-displacement responses of test specimens were studied and compared based on experimental observations. The test results indicated that high-strength (HS) RCSPSW system showed superior lateral load strength and acceptable deformation capability. The axial compressive load was found to have an indispensable effect on the ductility of both RCSW and RCSPSW, and an upper limit of axial compression ratio (0.5) is recommended for the application of HS RCSPSW in engineering practices. In addition, the design strength models were suggested for predicting the shear and flexure peak strength values of RCSPSW systems, and their applicability and reliability were verified by comparing with test results.
\end{abstract}

Keywords: composite shear wall; seismic behavior; quasi-static test; design strength model

\section{Introduction}

Shear walls serve as an effective structural element for resisting lateral load in tall buildings during seismic events. Conventional reinforced concrete shear walls (RCSW) are considered to be a cost-effective way for preventing structure collapse and ensure life-safety, which has been widely used in the design of low- and medium-rise building structures in seismic regions [1]. With the increase of building height, vertical axial load demands at lower floors exponentially grow, resulting in much thicker RCSW with the consideration of code-specified axial compression ratio limits [2-4]. Under such circumstance, excessively thick walls reduce the usable floor areas and increase the gravity load intensity, causing more seismic forces and severer structural damage. A review of past research work indicated that RCSW were mainly tested under low axial compressive loadings [1,5-7]. The first explanation is that reinforced concrete buildings are usually designed with a low axial compression ratio in high seismicity zones due to code limits. The second possibility is that conventional RCSW undergo significant structural damage in the form of undesirable failure patterns and deteriorated strength and ductility performances when subjected to high axial loadings [8]. Su [9] observed an abrupt out-of-plane compressive failure mode on experimentally tested RCSW under high axial compression ratios, and concluded that significant strength degradation and ductility deterioration would occur with the increase of the axial compression ratio. Moradi [10] conducted a comprehensive research study to set up a library of critical parameters that affect the behavior of shear walls based on 
a large amount of existing experimental tests, from which a predictive meta-model was developed to forecast the responses of desired shear walls.

Researchers explored the composite steel-concrete wall system by adding structural steel in the wall section, which potentially takes advantages of two materials' mechanical properties in order to improve the seismic performance of concrete shear walls under high axial loading and decrease the wall thickness. Dan [11] tested composite shear walls with I-shape or box-shape steel profiles that were placed at the extremities, and found that the lateral resistance and displacement ductility can be effectively improved by encased steel profiles. Tong and Hajjar [12,13] studied RCSW partially restrained by the steel frame at boundaries. It is concluded from the experimental results that this composite structural system provided adequate strength and stiffness to resist lateral forces and it would be applicable for low- and medium-rise buildings. Some researchers investigated the mixed use of RCSW and circular or rectangular concrete-filled steel tubular (CFST) columns [14-16]. The existing experimental results indicated that the strength and ductility performances were effectively improved by using CFST columns as the boundary elements. Previous research studies show that the structural steel is usually arranged at the extremities of reinforced concrete wall sections to form composite boundary elements; Cho [17], Esaki [18], and Zhou [19] conducted similar research work. For such a structural system, RCSW mainly serve as a shear-resisting component, while the function of composite boundary elements is to resist the overturning moment.

Apart from the use of composite boundary elements, researchers began to make use of the structural steel plate in the wall panel to further improve the lateral load performance in recent years. The concrete-steel plate composite shear wall system can be classified into two types: concrete-filled steel plate (CFSP) shear wall and steel-plate-embedded concrete shear wall. Hu and Nie [20,21] experimentally studied the CFSP composite shear walls and concluded that this wall system has larger lateral strength and deformation capacity under high axial compressive loadings. Hossain [22] and Rafie [23] reported similar findings on the shear wall system that consists of two skins of profiled steel sheeting with an in-fill of concrete. However, corrosion-protection and fire-protection layers are necessary for CFSP walls, because the steel plate is directly exposed to the environment, which increases the difficulty and complexity of construction. Therefore, the steel-plate-embedded concrete shear wall has advantages in engineering practice and has attracted the attention of researchers and practitioners.

Zhao [24] proposed a composite shear wall system comprising an infill steel plate with concrete panels that are attached on one side or both sides, and it is included in AISC Seismic Provisions and denoted as concrete stiffened steel plate shear wall (CSPSW) [25]. Note that a gap exists between concrete panel and the steel frame, thus the concrete panel merely works as a stiffer to prevent the bulking of the infill steel plate. The China Academy of Building Research (CABR) systematically studied the monolithic cast-in-place (CIP) RCSW with embedded steel plate, named as reinforced concrete-steel plate shear walls (RCSPSW). Figure 1 presents configurations of conventional RCSW and RCSPSW. The latter wall system consists of three major components, as depicted in Figure 1b. Concrete and steel reinforcement are identical to RCSW, while the I-shaped steel profiles are encased in boundary elements and the steel plate is embedded in the wall web. Sun [26] and Chen [27] investigated the shear and flexure behavior of normal-strength concrete-SP shear walls and demonstrated their good performances in both strength and deformation capabilities. Xiao [28] studied the effects of aspect ratios on lateral load performances of RCSPSW based on the previous research outcome. Subsequently, RCSPSW was successfully applied in the construction of high-rise buildings in China, such as: Shanghai Tower (632 $\mathrm{m}$ in height), Guangzhou East Tower (530 $\mathrm{m}$ in height), etc. [29]. 


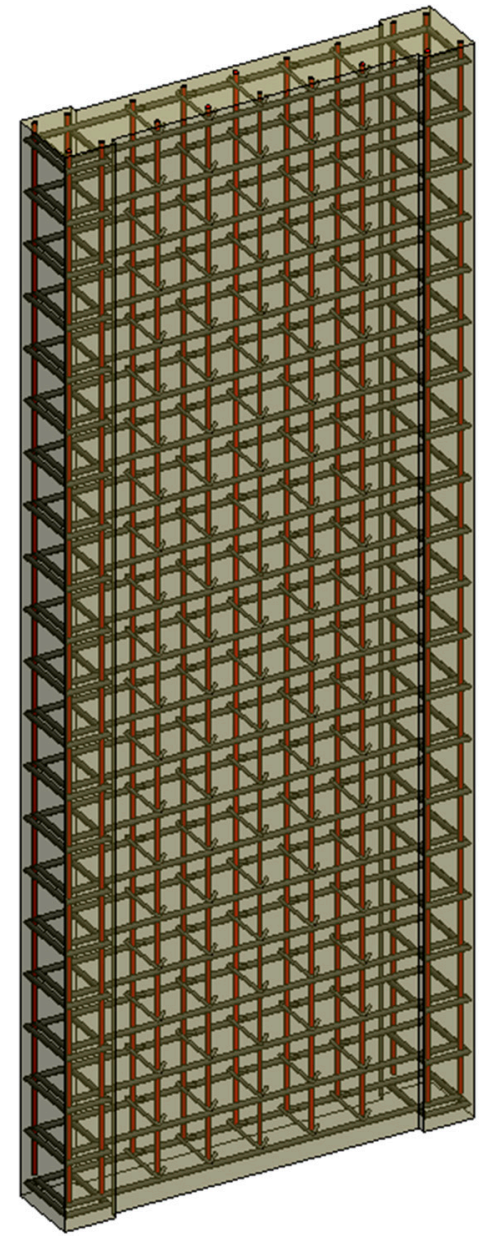

(a) Conventional reinforced concrete shear wall (RCSW)

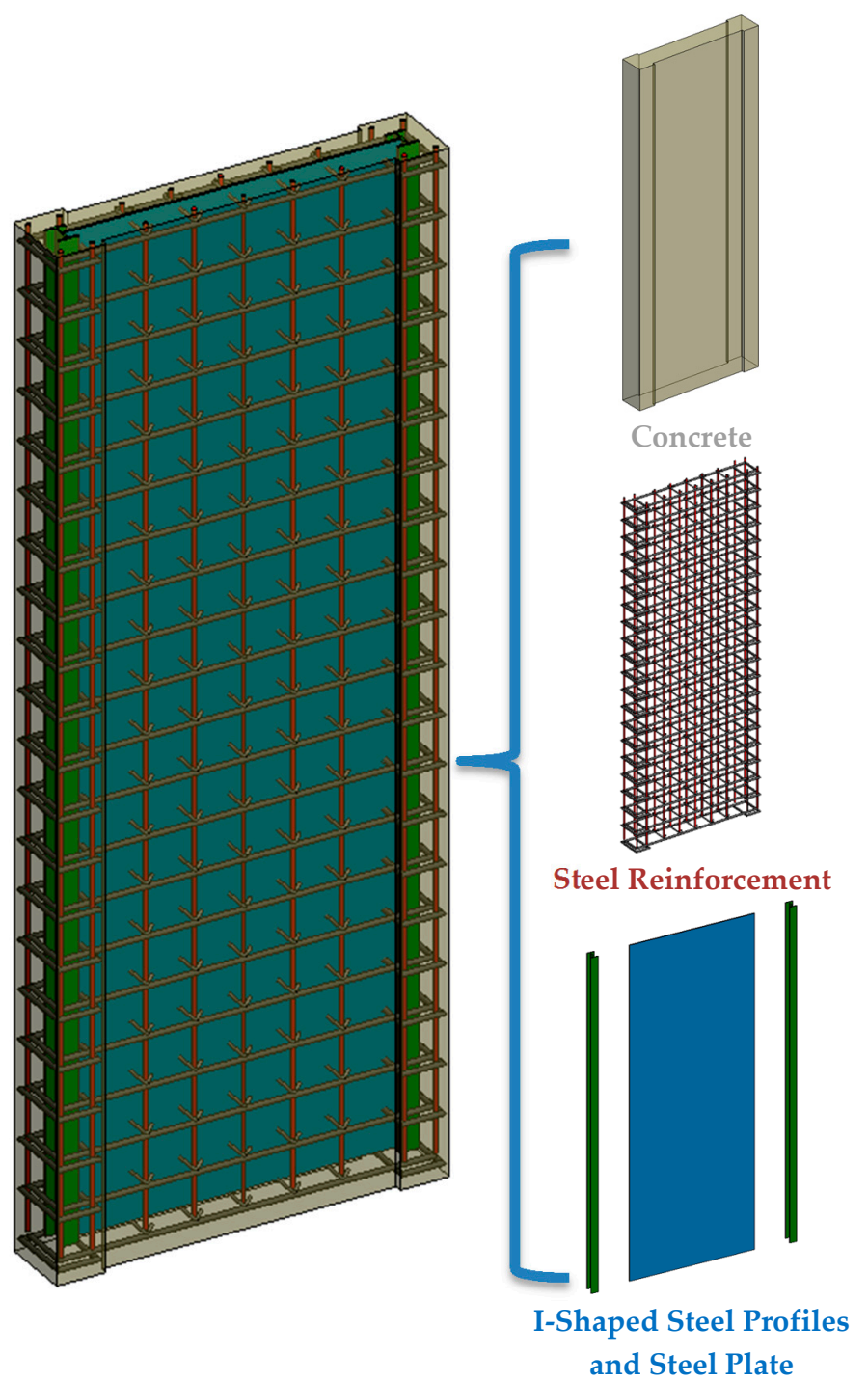

(b) Reinforced concrete-steel plate shear wall (RCSPSW)

Figure 1. The Concept of Reinforced Concrete-Steel Plate Composite Shear Wall System.

Not content with the benefits that RCSPSW brought, practitioners claimed that there is still a need to further reduce the wall thickness for super-tall buildings. In response to their expectation, the use of high-strength (HS) concrete in RCSPSW system becomes a potential option, because the high compressive strength of HS concrete can be an advantage when the walls are subjected to high axial compressive loadings. Meanwhile, whether the brittleness of HS concrete affects the ductility of RCSPSW remains in question. Jiang [30] and Xiao [31] investigated the compression-bending behavior of HS concrete shear walls and explore viable structural steel arrangements in the wall section to improve the deformability. The research outcome demonstrated that the flexure strength and ductility were effectively improved by the steel profiles encased in boundary elements. However, the overall seismic performances of HS RCSPSW system remain unknown to researchers. Additionally, the progressions of damage and failure modes of HS RCSPSW with different aspect ratios are not clear. The authors have conducted a comprehensive experimental investigation to study both shear and flexure behavior of HS RCSPSW in order to verify the reliability of HS RCSPSW system in engineering practices. Eleven high-strength concrete shear walls with two different aspect ratios (1.5 and 2.7) were constructed and tested under quasi-static reversed cyclic loading, including five conventional RCSW 
and six RCSPSW. Lateral load performance and failure modes are compared and discussed based on experimental observations. This paper emphasizes the experimental investigation and the design strength models of HS RCSPSW. Analytical and numerical models, as well as ways to incorporate axial-shear-flexure interaction, will be presented in a follow-up paper.

\section{Experimental Investigation}

\subsection{Specimen Properties}

Two batches of specimens were designed, constructed, and tested under quasi-static cyclic loadings, including RCSW and RCSPSW. Table 1 lists key information for test specimen configurations. Specifically, the specimens in Batch No.1 (RCSW 1-X and RCSPSW 1-X) with the aspect ratio (height/width, $h / b$ ) of 1.5 were designed to study the shear behavior, while the specimens in Batch No.2 (RCSW 2-X and RCSPSW 2-X) with a higher aspect ratio (2.7) were mainly designed for the flexure behavior investigation. These two aspect ratios were selected based on available references [1,8-10,14,19,32-35] and past engineering experience in high-rise building design to purposely achieve shear failure mode and flexure failure mode, respectively. Apart from the aspect ratio, the vertical axial load is another critical parameter that affects the seismic performance of shear wall specimens. As listed in Table 1, a wide range of vertical load values were applied on shear specimens $(900-1500 \mathrm{kN})$ and flexure specimens $(2180-3050 \mathrm{kN})$ in the quasi-static test to simulate different levels of axial loads that would be expected in the design of high-rise buildings. An axial compression ratio, $n$, is defined as the ratio of the applied vertical load to the compression capacity of the wall section and it is given by

$$
n=\frac{N}{f_{\mathrm{c}} A_{\mathrm{c}}+f_{\mathrm{ay}} A_{\mathrm{a}}+f_{\mathrm{py}} A_{\mathrm{p}}}
$$

where $N$ represents the vertical load that is applied by the hydraulic jack, $f_{\mathrm{c}}$ is the compressive strength of concrete, $f_{\text {ay }}$ and $f_{\text {py }}$ are yielding strength values of I-shape steel profiles and steel plate, and $A_{\mathrm{c}}, A_{\mathrm{a}}$, and $A_{\mathrm{p}}$ indicate the area of concrete section, boundary I-shaped steels, and embedded steel plate. For given vertical loads, axial compression ratio ranges from 0.33 to 0.50 for shear specimens and 0.42 to 0.70 for flexure specimens. Note that these values are relatively high for shear walls in building structures, and very few past research work has been performed while using such high axial compression ratios.

Figure 2 shows the cross-sectional dimensions and reinforcing detailing for RCSW and RCSPSW. All of the specimens were designed with the target concrete cubic compressive strength of $f_{\mathrm{c}, \text { cube }}^{\prime}=80 \mathrm{MPa}$. The use of high-strength concrete not only effectively increases the lateral capacity, but it also significantly reduces the required wall thickness due to code-specified axial compression ratio limits in the design of tall buildings [3,4]. The geometrical sizes and steel reinforcement were carefully designed, so that desirable failure mechanisms would take place in the test for different batches of specimens. For instance, longitudinal boundary reinforcements with relatively smaller diameters ( $\varphi 8$ and $\varphi 10)$ were purposely implemented in specimens with the aspect ratio of 2.7, so as to observe a flexure mode of failure prior to achieving a shear mode of failure. The geometric dimensions and reinforcement arrangement were identical for RCSW and RCSPSW specimens with specified aspect ratios. The shear specimens consist of an $800 \mathrm{~mm}$ wide by $80 \mathrm{~mm}$ thick wall web and two $100 \mathrm{~mm}$ wide by $120 \mathrm{~mm}$ thick boundary elements. As for flexure specimens, the thickness values for the web and boundary elements are $150 \mathrm{~mm}$ and $190 \mathrm{~mm}$, respectively. The distances that were measured from the top surface of the footing to the lateral loading point are $1.2 \mathrm{~m}$ and $2.16 \mathrm{~m}$ for shear and flexure specimens, as shown in Figure 2. For the RCSPSW specimens, I-shaped steels in boundary elements were welded to the $5 \mathrm{~mm}$ thick steel plate that was embedded in the wall web, and steel studs or tie bars were used to ensure the bonding strength between the concrete and steel plate. Longitudinal reinforcement was placed in 
boundary elements, and steel ratios of $16.9 \%$ and $1.35 \%$ were used for shear and flexure specimens, respectively. Table 1 lists the steel reinforcement ratios in wall web.

Table 1. Test Specimen Configurations.

\begin{tabular}{|c|c|c|c|c|c|c|c|}
\hline \multirow{2}{*}{$\begin{array}{l}\text { Batch } \\
\text { Number }\end{array}$} & \multirow{2}{*}{$\begin{array}{l}\text { Specimen } \\
\text { Number }\end{array}$} & \multirow{2}{*}{$\begin{array}{l}\text { Aspect } \\
\text { Ratio }\end{array}$} & \multicolumn{3}{|c|}{ Steel Reinforcement Ratio } & \multirow{2}{*}{$\begin{array}{l}\text { Vertical } \\
\text { Load (kN) }\end{array}$} & \multirow{2}{*}{$\begin{array}{c}\text { Axial } \\
\text { Compression } \\
\text { Ratio }\end{array}$} \\
\hline & & & $\begin{array}{c}\text { Web } \\
\text { Longitudinal }\end{array}$ & $\begin{array}{c}\text { Web } \\
\text { Transverse }\end{array}$ & $\begin{array}{c}\text { Boundary } \\
\text { Longitudinal }\end{array}$ & & \\
\hline \multirow{5}{*}{1} & RCSW 1-1 & \multirow{5}{*}{1.5} & \multirow{5}{*}{$0.71 \%$} & \multirow{5}{*}{$0.71 \%$} & \multirow{5}{*}{$16.9 \%$} & 900 & 0.45 \\
\hline & RCSW 1-2 & & & & & 1000 & 0.50 \\
\hline & RCSPSW 1-1 & & & & & 1000 & 0.33 \\
\hline & RCSPSW 1-2 & & & & & 1380 & 0.45 \\
\hline & RCSPSW 1-3 & & & & & 1500 & 0.50 \\
\hline \multirow{6}{*}{2} & RCSW 2-1 & \multirow{6}{*}{2.7} & \multirow{6}{*}{$0.38 \%$} & \multirow{6}{*}{$0.67 \%$} & \multirow{6}{*}{$1.35 \%$} & 2180 & 0.50 \\
\hline & RCSW 2-2 & & & & & 2610 & 0.60 \\
\hline & RCSW 2-3 & & & & & 3050 & 0.70 \\
\hline & RCSPSW 2-1 & & & & & 2180 & 0.42 \\
\hline & RCSPSW 2-2 & & & & & 2610 & 0.50 \\
\hline & RCSPSW 2-3 & & & & & 3050 & 0.58 \\
\hline
\end{tabular}

RCSW \#-\# represents conventional reinforced concrete shear walls and RCSPSW \#-\# represents new reinforced concrete-steel plate composite shear walls.

Table 2 lists key material properties of test specimens. The 28-day cubic compressive strength, $f_{\mathrm{ck}, \mathrm{cube}}^{\prime}$ for shear specimens and flexure specimens are 72.3 MPa and 84.1 MPa, respectively. Two types of steel reinforcements (HPB235 and HRB 335) were used in the wall specimens. Table 2 summarizes the measured yield strength $f_{\mathrm{yk}}$ and ultimate strength $f_{\mathrm{tk}}$ of steel reinforcements and steel plates.

Table 2. Material Properties.

\begin{tabular}{|c|c|c|c|c|c|c|c|c|}
\hline \multirow{3}{*}{$\begin{array}{l}\text { Material } \\
\text { Specimen } \\
\text { Number }\end{array}$} & \multicolumn{2}{|c|}{ Concrete } & \multicolumn{4}{|c|}{ Steel Reinforcement } & \multicolumn{2}{|c|}{ Steel Plate } \\
\hline & \multirow{2}{*}{$\begin{array}{l}\text { Compressive } \\
\text { Strength } \\
f_{\text {dk,cube }} \\
\text { (MPa) }\end{array}$} & \multirow{2}{*}{$\begin{array}{c}\text { Tensile } \\
\text { Strength } \\
f_{\text {ctk }} \\
(\mathrm{MPa})\end{array}$} & \multicolumn{2}{|c|}{$\begin{array}{l}\text { Yield Strength } \\
F_{\mathrm{yk}}(\mathrm{MPa})\end{array}$} & \multicolumn{2}{|c|}{$\begin{array}{l}\text { Ultimate Strength } \\
\qquad f_{\mathrm{tk}}(\mathrm{MPa})\end{array}$} & $\begin{array}{c}\text { Yield } \\
\text { Strength } \\
f_{\mathrm{yk}}(\mathrm{MPa})\end{array}$ & $\begin{array}{r}\text { Ultimate } \\
\text { Strength } \\
f t_{\mathrm{k}}(\mathrm{MPa})\end{array}$ \\
\hline & & & HPB235 & HRB335 & HPB235 & HRB335 & & \\
\hline RCSW 1-X & \multirow{2}{*}{72.3} & \multirow{2}{*}{3.75} & \multirow{2}{*}{267} & \multirow{2}{*}{454} & \multirow{2}{*}{403} & \multirow{2}{*}{628} & & \\
\hline RCSPSW 1-X & & & & & & & 367 & 477 \\
\hline RCSW 2-X & \multirow{2}{*}{84.1} & \multirow{2}{*}{3.93} & \multirow{2}{*}{295} & \multirow{2}{*}{441} & \multirow{2}{*}{419} & \multirow{2}{*}{595} & & \\
\hline RCSPSW 2-X & & & & & & & 322 & 435 \\
\hline
\end{tabular}



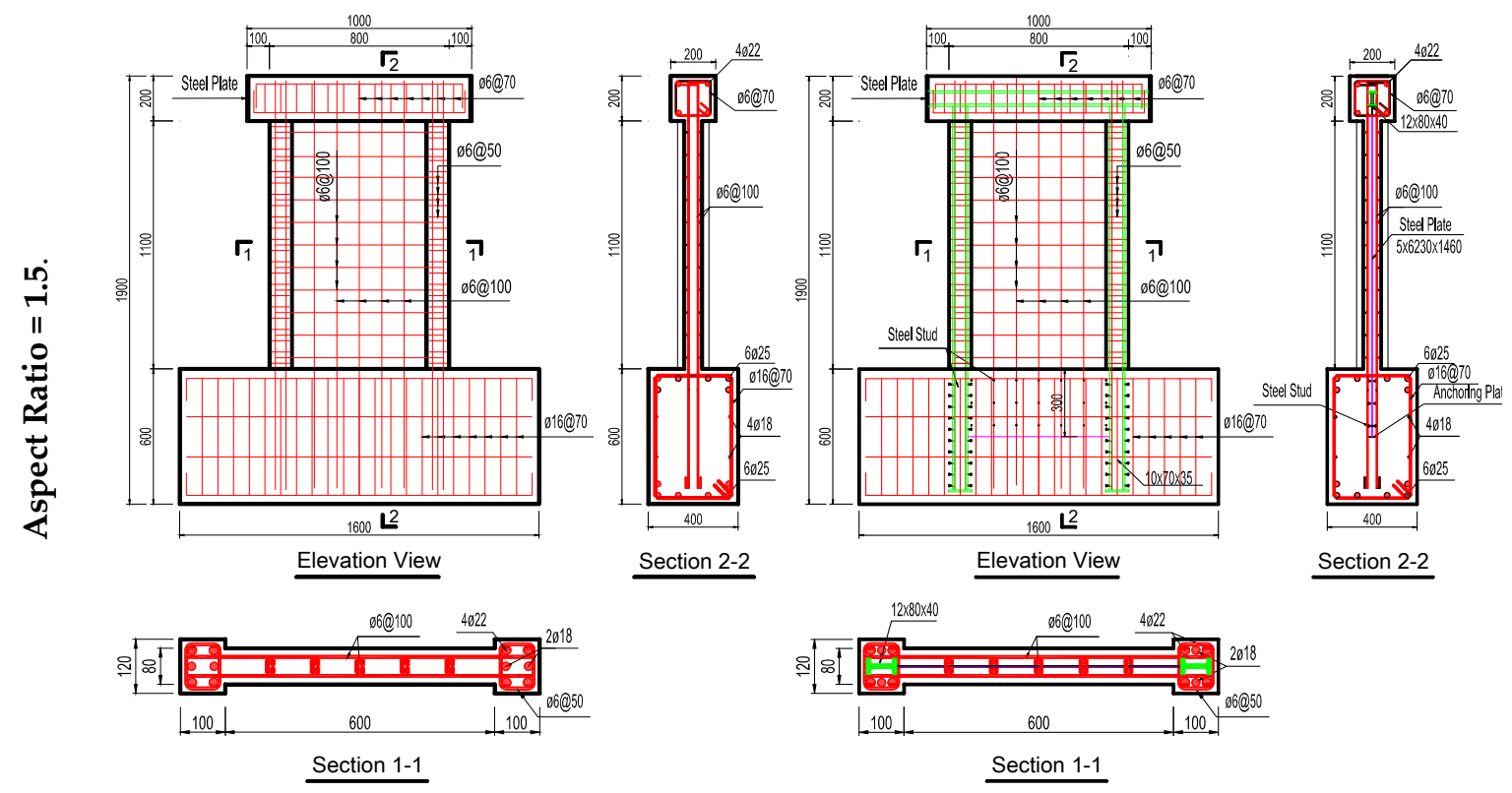

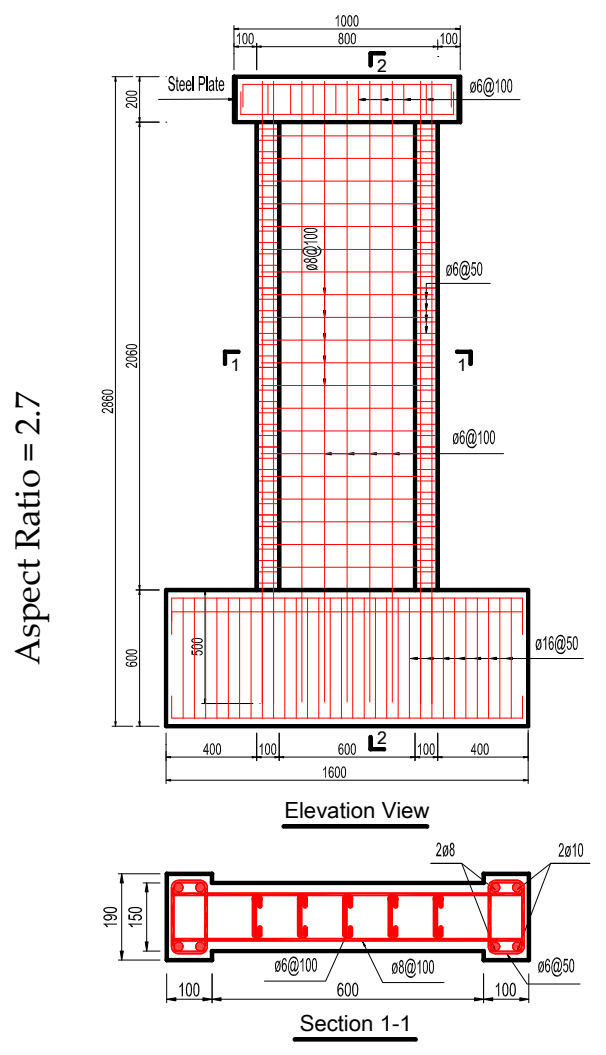

(a) Conventional RCSW

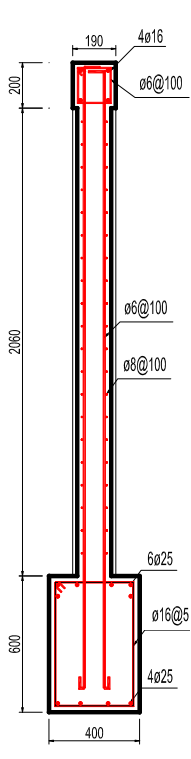

Section 2-2
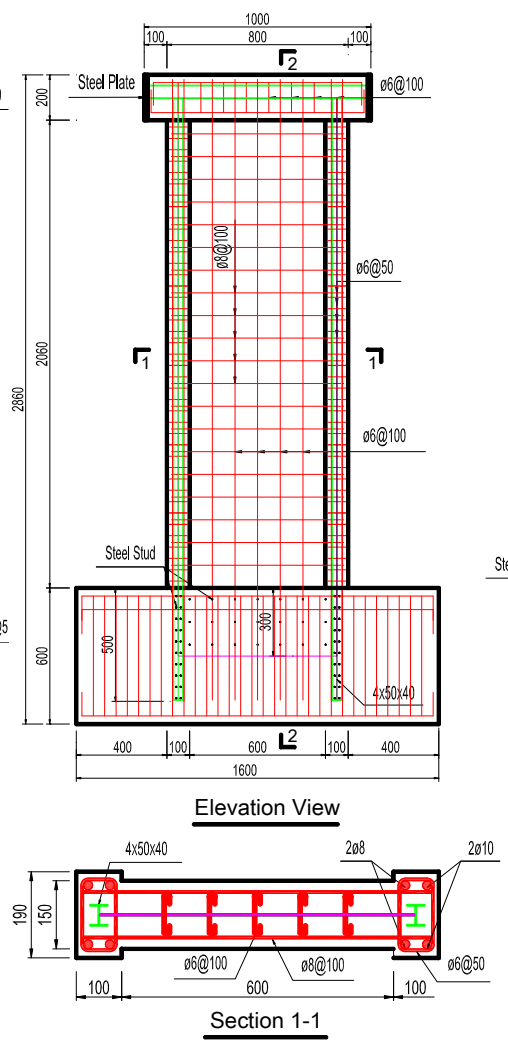

(b) RCSPSW

Figure 2. Cross-sectional Dimensions and Reinforcement Details of RCSW and RCSPSW.

\subsection{Test Setup, Instrumentation and Load Protocol}

The quasi-static load test was conducted on shear and flexure specimens to evaluate the seismic performance of the HS RCSPSW system. Figure 3 presents the experimental setup details. Wall specimen was anchored onto the laboratory rigid floor with fasteners through the footing. One $1500 \mathrm{kN}$ servo-controlled hydraulic actuator along the east-west direction was installed on the reaction wall to provide racking loads on the specimen during the reversed cyclic load test. The vertical load was 
applied through a $4000 \mathrm{kN}$ capacity hydraulic jack that was installed beneath the rigid steel frame, and the vertical load is uniformly spread along the top surface of the wall specimen by means of two steel distribution beams. Out-of-plan steel bracings were used to keep the specimen movement in-plane and avoid twisting during testing, as can be seen in the setup photograph (Figure 3d).

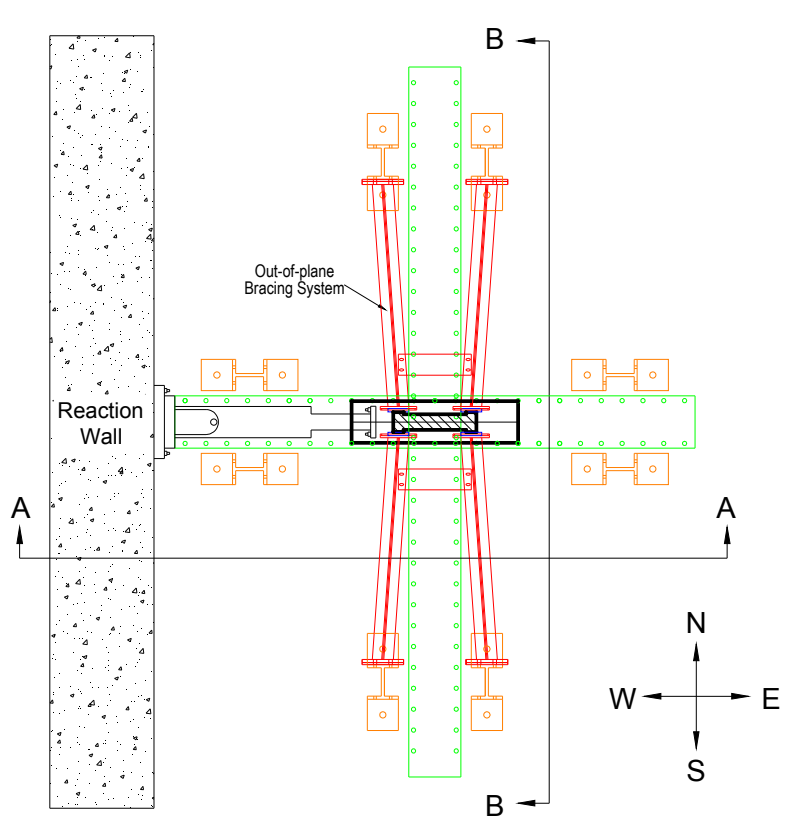

(a) Plan View

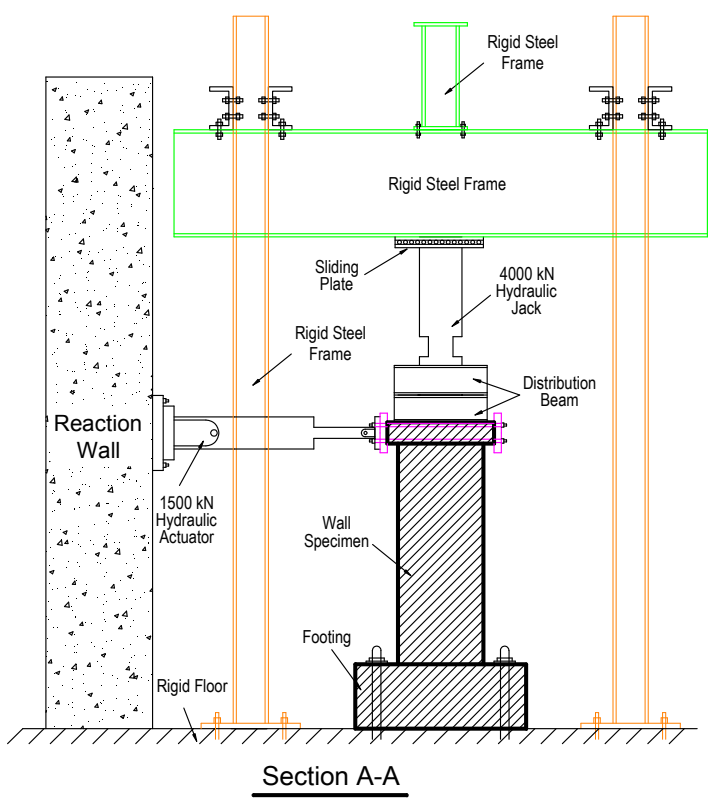

(c) Side View

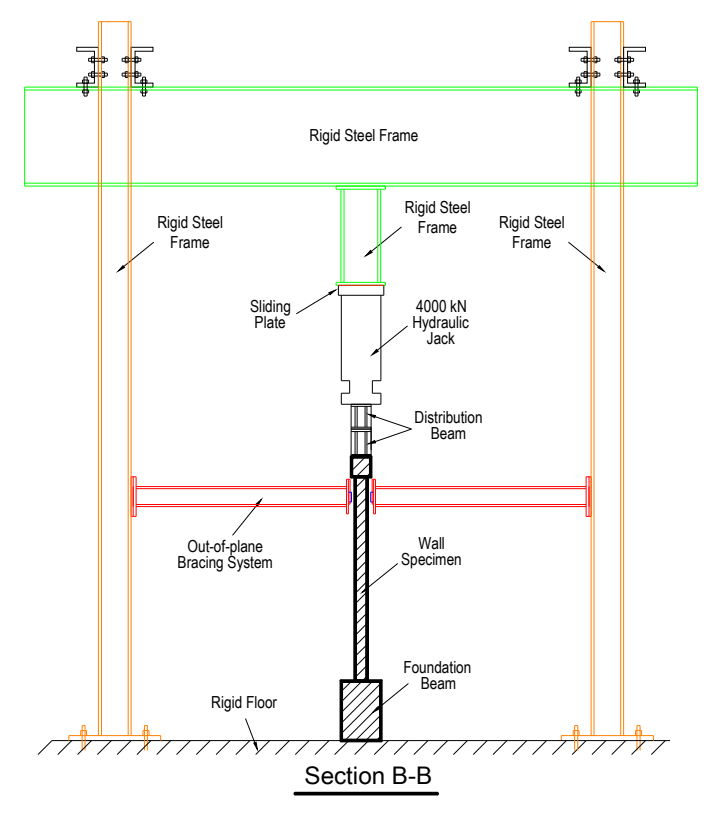

(b) Front View

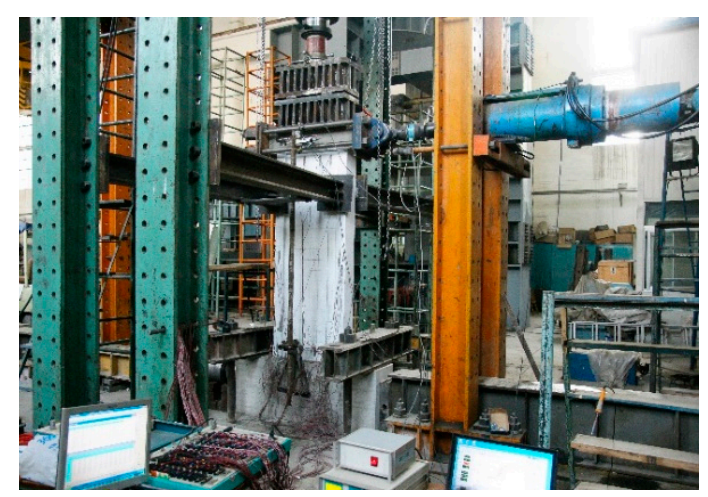

(d) Photograph of Experimental Setup

Figure 3. Details of Experimental Setup (a) Plan View; (b) Front View (Section B-B); (c) Side View (Section A-A); and, (d) Photograph of Experimental Setup.

Figure 4 depicts the instrumentation layout of test specimens. The load cells were installed inside the hydraulic jack and hydraulic actuator to measure the vertical and lateral forces during the test. A Linear Variable Differential Transformer (LVDT) was attached to the surface of the loading beam to measure the displacement under racking loads. As shown in Figure $4 c$, the strain rosettes with $60-\mathrm{mm}$ gauge length were attached in diagonals on the concrete surface of shear specimens to capture 
the shear cracks. In terms of flexure specimens, individual concrete strain gauges with 60-mm gauge length were installed on the bottom part of wall panel to capture the flexure-tension cracks. Similar strain rosette and strain gauge arrangements were adopted for the embedded steel plate to measure the strain values, but the gauge length is much smaller $(5 \mathrm{~mm})$. Additionally, individual strain gauges with 5-mm gauge length were used to monitor the longitudinal strains in the vertical and horizontal reinforcements, as well as the I-shape steel profiles.
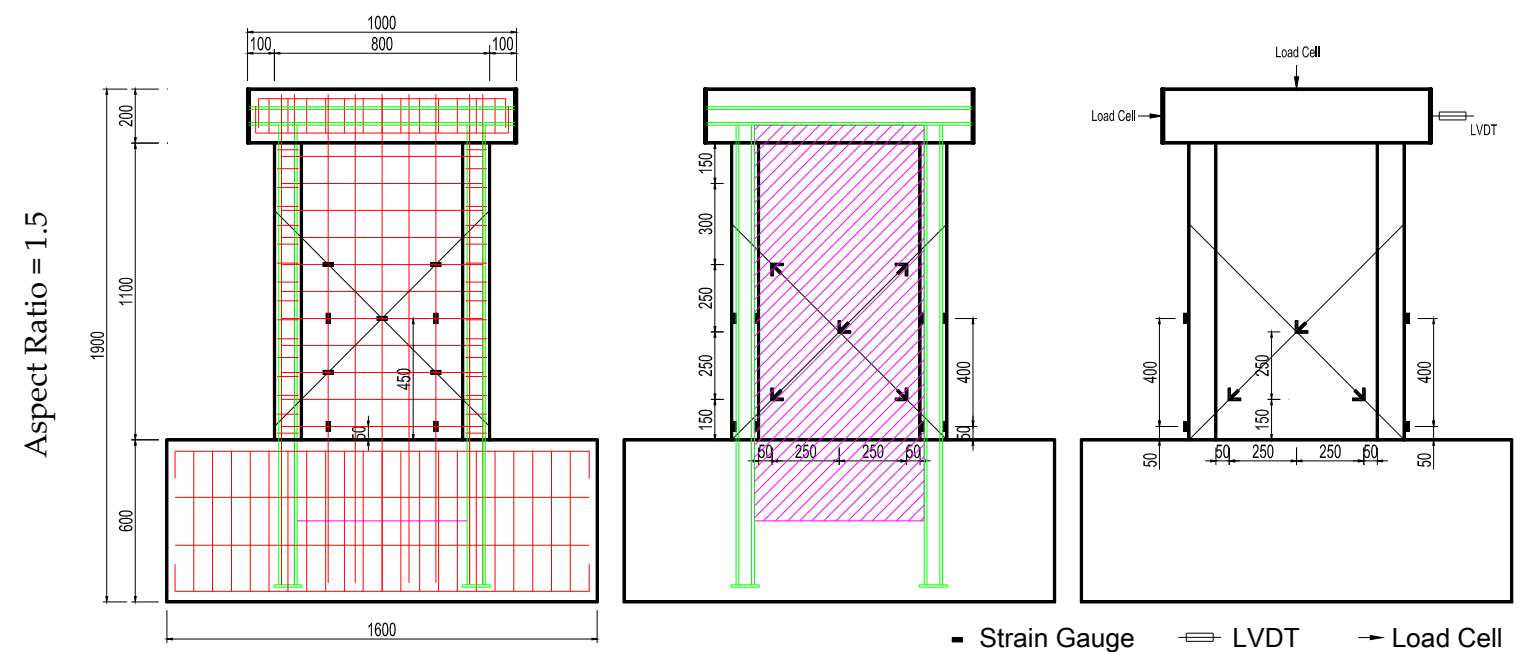

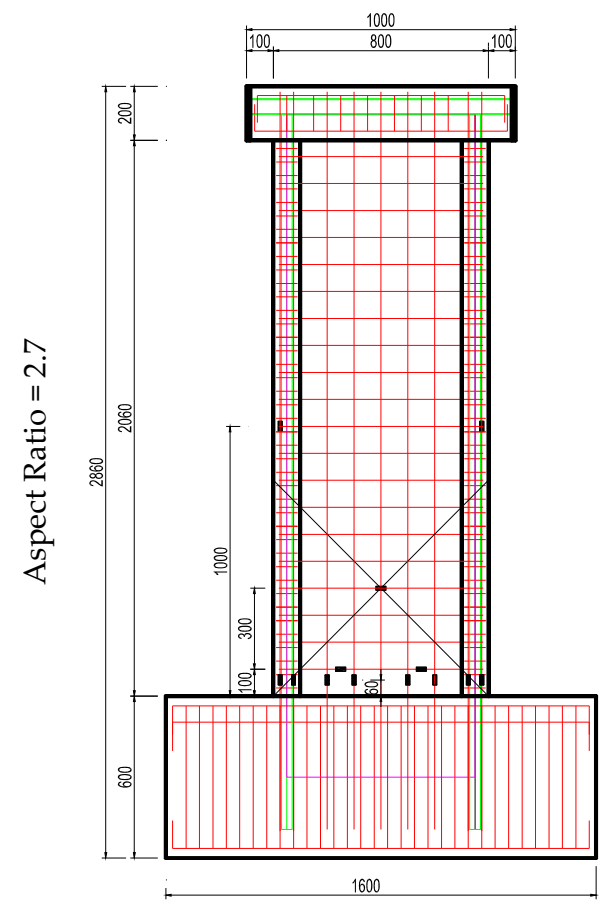

(a) Steel Reinforcements

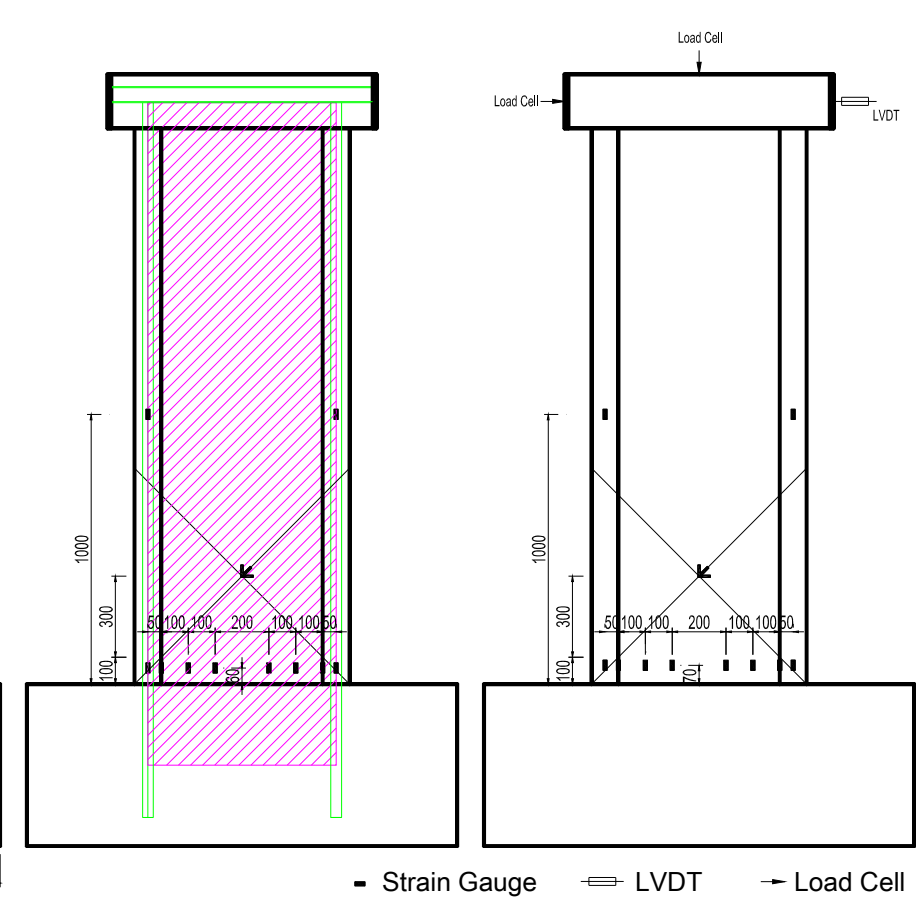

(b) Steel Profiles and Steel Plate

(c) Concrete Surface

Figure 4. Instrumentation Layout of Test Specimens (a) Strain Gauges on Steel Reinforcements; (b) Strain Gauges on I-shaped Steel Profiles and Steel Plate; and. (c) Strain Gauges, Linear Variable Differential Transformer (LVDT) \& Load Cells on Concrete.

Figure 5 shows the cyclic lateral displacement history that was used in the quasi-static test. The specified axial compressive load was constantly applied on the top surface of wall specimen throughout the test. The two phase mixed lateral force/displacement control cyclic loading scheme was used herein, as specified in Chinese Specification for Seismic Test of Buildings [36] and suggested 
by Zhang [8], Zhou [19], and Nie [21]. Force control cycles were adopted before yielding occurs in shear wall specimens, and only one cycle is applied in each load step. It is possible to determine the accurate lateral forces corresponding to the first visible crack initiation and crack pattern propagation with dividing the first phase into different levels of load cycles. Once the yielding has commenced, displacement-control tests were performed by gradually increasing reversed cyclic displacements in the form of triangular waves and two repeated cycles of the same displacement amplitude were applied for each displacement increment. The magnitude of displacement in each level equals multiple times of the displacement at yield, $y=n \Delta_{\mathrm{y}}$, which also indicates the increasing ductility level at each cycle. The reversed cyclic load test ends until the lateral force drops below $85 \%$ of the maximum lateral load capacity. The yield dispalcemnt value, $\Delta_{\mathrm{y}}$, is taken as $2 \mathrm{~mm}$ and $6 \mathrm{~mm}$ for shear and flexure specimens, respectively, in this series of experimental tests based on a trial test recording.

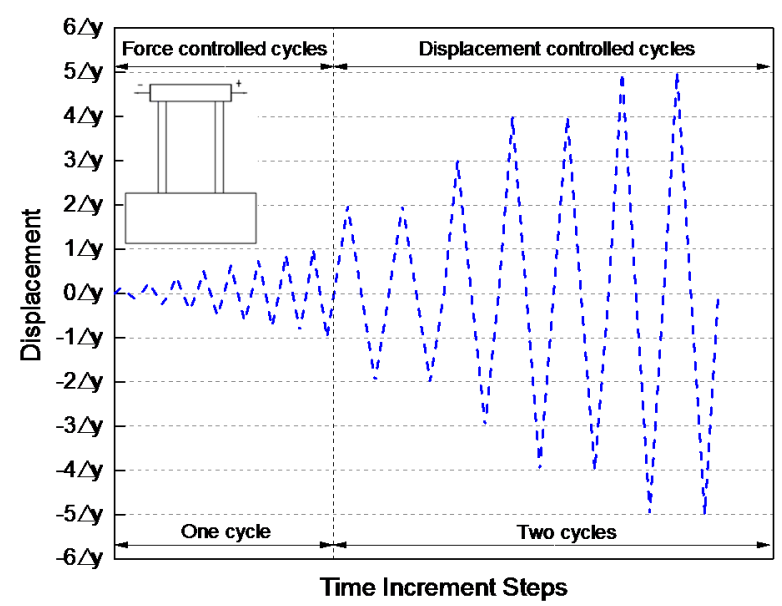

Figure 5. Cyclic Displacement History for Quasi-static Test of Shear Wall Specimens. $\Delta y$ indicates the lateral displacement when the wall specimen shows yielding behavior.

\subsection{Analysis Methods for Experimental Observations}

Key information was inferred from the instrumentation recordings in the reversed cyclic load test to evaluate the seismic performance of shear walls, including hysteresis curve, skeleton curve, ductility, energy dissipation ability, etc. Figure 6a presents a typical hysteresis curve that is directly obtained by the lateral force and displacement readings from the load cell and LVDT, and the skeleton curve is determined from the hysteresis curve by joining the peak-load tips of each primary loop.

Ductile structures are preferable in the earthquake-resistant design. Structural members are required to undergo large amplitude lateral deformations without the substantial loss of strength and also dissipate significant amounts of energy in those cyclic deformations. A displacement ductility factor, $\mu$, is defined as the ultimate displacement, $\Delta_{\mathrm{u}}$, to the displacement at yield, $\Delta_{\mathrm{y}}$, and it is given by

$$
\mu=\frac{\Delta_{\mathrm{u}}}{\Lambda_{\mathrm{y}}}
$$

where the ultimate displacement $\left(\Delta_{\mathrm{u}}\right)$ is defined as displacement value that corresponds to $85 \%$ of peak load on descending branch of the skeleton curve as specified in Chinese Specification for Seismic Test of Buildings [36] and suggested by Dan [11], Tong [12], and Liao [37]. The yield displacement $\left(\Delta_{y}\right)$ is determined with the method that Priestley recommended [38], which will be described in detail later.

The definition of the yield point in the skeleton curve often causes difficulty in the calculation of ductility factors. Figure $6 \mathrm{~b}$ illustrates three alternative definitions of the yield displacement and the corresponding yield strength. Priestley [38] suggested that the yield displacement be determined by the equivalent elasto-plastic system with the secant stiffness at $75 \%$ of the peak lateral load, $P_{\max }$ (Figure 6(b1). Mahin [39] proposed the use of the equivalent elasto-plastic system with the same energy 
absorption from the origin to the peak lateral load level, as shown in Figure 6(b2)). In ASTM E2126 [40], an equivalent energy elastic-plastic (EEEP) is defined as an elastic-plastic curve that circumscribes an area that is equal to the area enclosed by the skeleton curve between the origin, the displacement axis, and the ultimate displacement (Figure 6(b3)). Park [41] claimed that the first definition is the most realistic option to determine the yield displacement for reinforced concrete structures, which will be used herein to calculate the displacement ductility factors of test shear wall specimens.

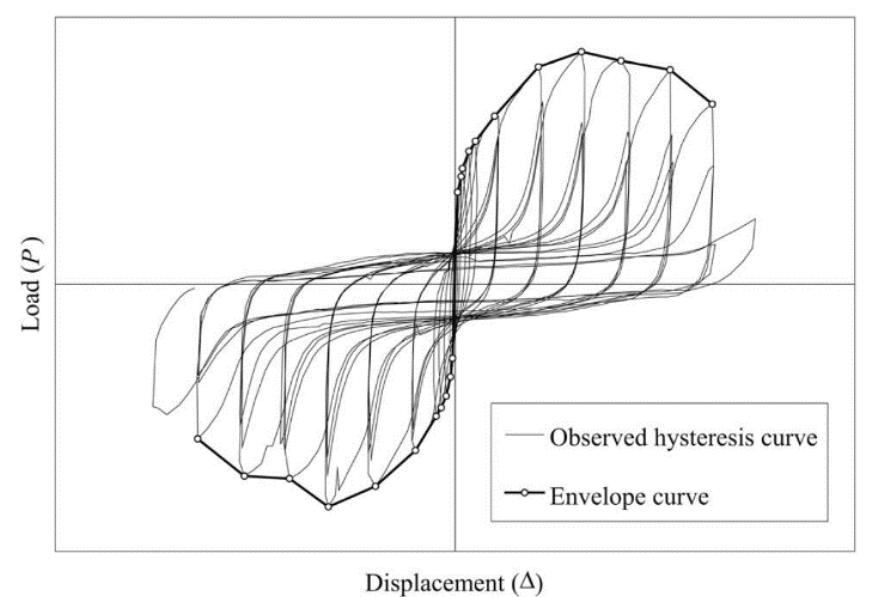

(a) Hysteresis Curve and Skeleton Curve (Excerpt from ASTM E2126-11)

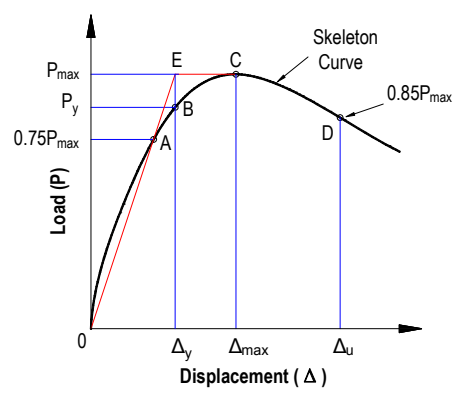

1. Reduced Stiffness Equivalent Elasto-platic Yield

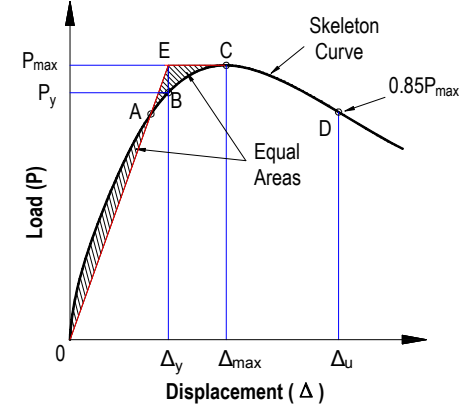

2. Equivalent Areas

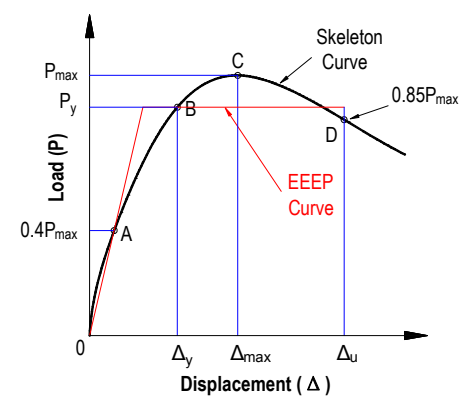

3. Equivalent energy elasticplastic (EEEP) Curve (ASTM E2126)

(b) Alternative Definitions for Yield Strength and Yield Displacement

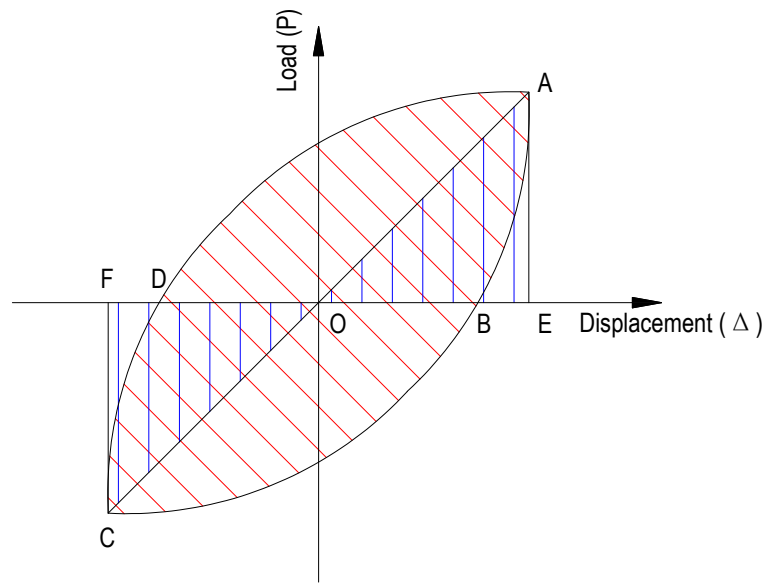

(c) Definition for Equivalent Viscous Damping Coefficient

Figure 6. Analysis Methods for Experimental Observations (a) Hysteresis Curve and Skeleton Curve; (b) Yield Strength and Yield Displacement; and, (c) Equivalent Viscous Damping Coefficient. 
As shown in Figure 6a, structural members have some deformation capacity beyond the peak lateral load, $P_{\max }$, with undergoing a small reduction of strength. Thus, it is reasonable to recognize part of the post-peak deformation capacity, and the ultimate displacement is defined herein as the point when the load carrying capacity drops below $85 \%$ of the peak strength on descending branch of the skeleton curve, or when severe collapse failure takes place in the specimen, whichever occurs first.

The ductility factor is defined in terms of deformation, which provides no indication regarding the energy dissipation capacity of the structural members. The equivalent viscous damping (EVD) coefficient is considered to be a critical parameter in evaluating the energy dissipation ability of given structural members. For shear wall specimens subjected to reversed cyclic loadings, the EVD coefficient can be obtained by a function of the dissipated energy of the structural member, $E_{\mathrm{Di}}$, and the elastic energy stored in an equivalent viscous system, $E_{\mathrm{Si}}$, in cycle $i$ [42]. The energy that is dissipated by the structural member can be expressed as the area enclosed by the hysteresis loop $\left(S_{\mathrm{ABCD}}\right)$ and the stored energy is measured by areas within two triangles of the first and third quadrants $\left(S_{\mathrm{AOF}}\right.$ and $\left.S_{\mathrm{COF}}\right)$, as depicted in Figure 6c. The formal equation is given by

$$
\zeta_{\mathrm{ei}}=\frac{1}{2 \pi} \frac{E_{\mathrm{Di}}}{E_{\mathrm{Si}}}
$$

where $\zeta_{\mathrm{ei}}$ is the EVD coefficient for the cycle $i$.

\section{Experimental Results and Discussions}

A total of 11 shear wall specimens were tested under reversed cyclic loadings. The progressions of damage and failure modes for all specimens were observed throughout the test procedure. Performance parameters, including lateral load capacity, ultimate displacement, ductility factor, and EVD coefficient, were determined.

\subsection{Progression of Damage and Failure Modes}

Specimen RCSW 1-1 was conceived to represent a conventional RCSW with low aspect ratio (1.5). The first inclined crack was observed on the web surface during the $200 \mathrm{kN}$ load step, and then horizontal tension cracks formed at the lower part of boundary elements during the $300 \mathrm{kN}$ load step. Afterwards, transverse steel bars in the web and vertical steel bars at the extreme end of the boundary toe yielded at the load step of $400 \mathrm{kN}$, and the corresponding lateral displacement value is $2 \mathrm{~mm}$. In the following steps, displacement-controlled cycles were adopted and the inclined cracks gradually extended. The quantity of boundary horizontal cracks and the web inclined cracks significantly increased and the crack width reached up to $0.35 \mathrm{~mm}$ during the $4 \mathrm{~mm}$ load step $(0.33 \%$ drift ratio). The specimen achieved the maximum lateral load capacity at the $8 \mathrm{~mm}$ load step $(0.67 \%$ drift ratio) and the concrete cover started spalling during that load step. Significant concrete spalling was observed at both wall web and boundary toes, and the lateral load strength substantially reduced at the $16 \mathrm{~mm}$ load step (1.33\% drift ratio), when the test ended.

In general, specimen RCSW 1-1 showed a typical shear damage pattern as the representative of shear specimens. On the contrary, the flexural damage pattern is primarily observed in specimens with the aspect ratio of 2.7 and the damage progression of RCSW 2-1 is described in detail as an example. The horizontal flexure-tension crack is initiated at the $350 \mathrm{kN}$ load step in the bottom of the boundary elements, and it was then extended to the web surface with the crack width expanding up to $0.35 \mathrm{~mm}$ at the $400 \mathrm{kN}$ load step. Longitudinal steel bars in the boundary elements yielded at the $450 \mathrm{kN}$ load step and the lateral displacement reaches $11 \mathrm{~mm}(0.51 \%$ drift ratio). Vertical cracks in boundary toes were observed at the $15 \mathrm{~mm}$ load step $(0.69 \%$ drift ratio) with little concrete cover spalling, and the existing cracks were further diagonally extended to the web surface with the crack widths increasing up to $1.4 \mathrm{~mm}$. Subsequently, the specimen reached the maximum positive and negative lateral loading capacities with more severe concrete spalling at $+21 \mathrm{~mm}(0.97 \%$ drift ratio) and $-27 \mathrm{~mm}(1.25 \% \mathrm{drift}$ 
ratio) load steps. The test of specimen RCSW 2-1 ended after the cycle of $39 \mathrm{~mm}$ ( $1.81 \% \mathrm{drift}$ ratio) when the boundary steel rebar fractured and concrete at wall toes also crushed.

Figures 7 and 8 presents crack distributions at different inter-story drifts (ISD) and photographs of failure patterns for all of the specimens. Three ISD values $(0.1 \%, 0.33 \%$, and $1.0 \%)$ were selected to evaluate in-service performances of shear walls when subjected to minor, moderate, and major earthquakes. It can be seen from Figures $7 \mathrm{a}$ and $8 \mathrm{a}$ that no cracks or very few cracks were observed at the ISD of $0.1 \%$ and all of the specimens remain in the elastic range at that stage. As the level of ISD increased, more web inclined cracks and boundary horizontal cracks occurred in the shear specimens with the crack width expanding. In terms of flexure specimens, the quantity of boundary horizontal cracks increased, some of which diagonally extended to the web, forming flexure-shear cracks. When the ISD value reached $1 \%$, very dense cracks were distributed on the wall surface. In contrast to crack-riddled shear specimens (Figure 7a), the cracks were mainly distributed in the lower half of flexure specimens, and the upper half almost kept undamaged (Figure 8a). As compared to the RCSW specimens, more densely-distributed cracks were shown in the RCSPSW specimens, but the crack widths are much smaller based on observations. In addition, with the increase of the axial compressive load, the quantity of distributed cracks becomes less and the crack width is smaller due to the compaction of compression forces.

Figure $7 \mathrm{~b}$ shows the failure modes for shear specimens. Significant spalling of concrete cover along the shear cracks in wall web and concrete crushing in boundary toes were observed in the RCSW shear specimens. As for RCSPSW shear specimens, the embedded steel plate tended to buckle at the failure point, accompanied by severe concrete spalling in the lower part of the wall web. When it comes to flexure specimens, concrete crushing at the toe and longitudinal steel rebar facture usually occurred in the boundary elements, as shown in Figure 8b. Severe spalling of concrete cover in the bottom of wall web is also observed in specimen RCSPSW 2-1. In general, the RCSPSW specimens show a denser crack distribution but the crack width is smaller. Moreover, the damage observed in RCSPSW specimens is not as severe as RCSW.

The failure modes of shear wall specimens were controlled by axial-flexure-shear interactions that were affected by a variety of parameters, including aspect ratio, axial compression ratio, structural steel arrangement, etc. With the variation of key parameters, aspect ratio, in particular, the failure characteristics transit from 'shear failure' to 'flexural failure'.

Figure 9a shows a photograph of shear failure patterns referred to past research studies $[1,19,43]$. Shear critical walls mainly exhibit a diagonal cracking pattern on the wall surface. The first inclined crack at an angle of approximately $45^{\circ}$ is initiated by the shear stress at the corner of the wall and then extends to the mid portion. Upon further loading cycles, new inclined cracks occur and existing cracks extend; the strains of reinforcing bars and the widths of intercrossing main diagonal cracks are developed until the peak lateral load is attained. Afterwards, the spalling and crushing of concrete take place at corners and the diagonal cracking becomes severer until the wall fails. In general, shear-critical walls usually fail by diagonal tension or diagonal compression. Typical shear failure characteristics include the formation of diagonal cracks, yielding of reinforcing bars, and spalling of the concrete cover at the intercrossing diagonal cracks region or wall toes, as illustrated in Figure 9b. 


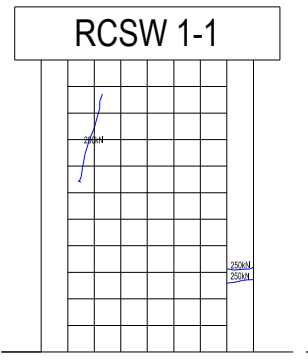

$1 / 1000$

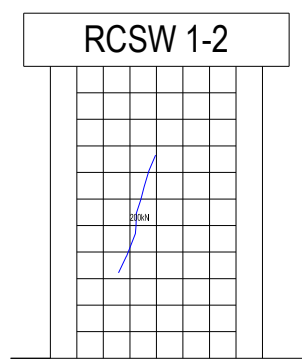

$1 / 1000$

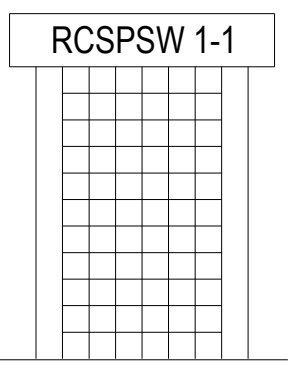

1/1000

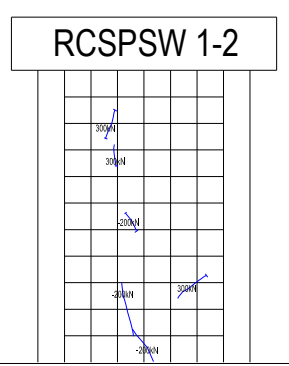

$1 / 1000$

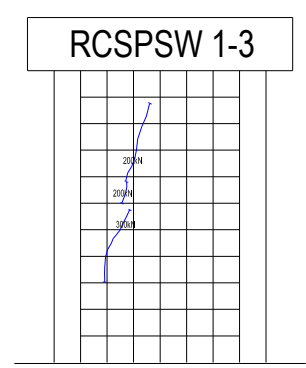

$1 / 1000$

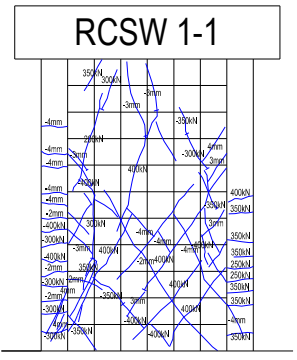

$1 / 300$

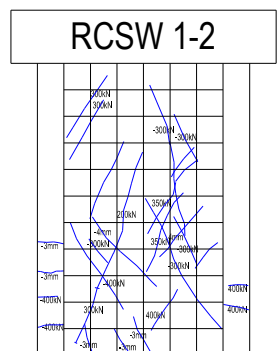

$1 / 300$

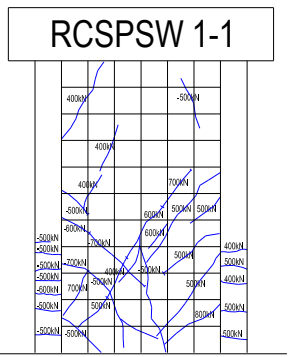

$1 / 300$

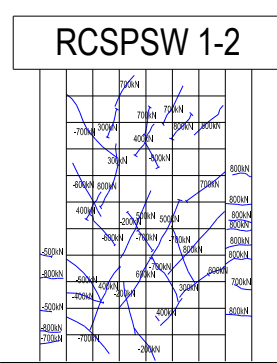

$1 / 300$

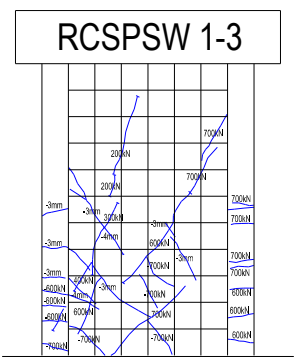

$1 / 300$

(a) Crack Distribution at Different Inter-story Drifts

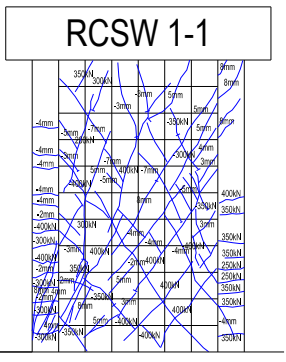

$1 / 100$

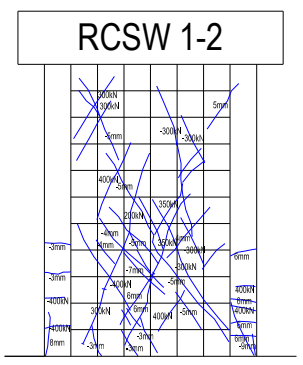

$1 / 100$

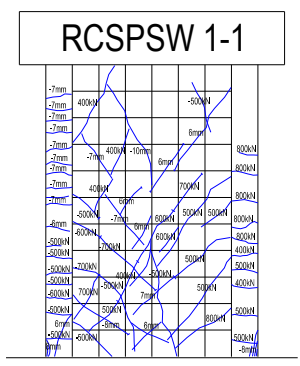

$1 / 100$

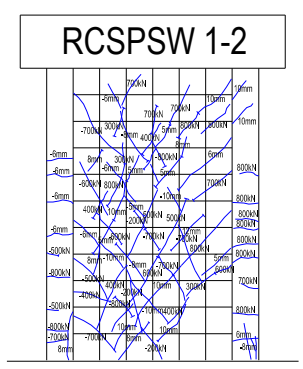

$1 / 100$

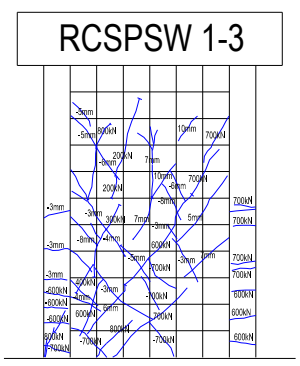

$1 / 100$
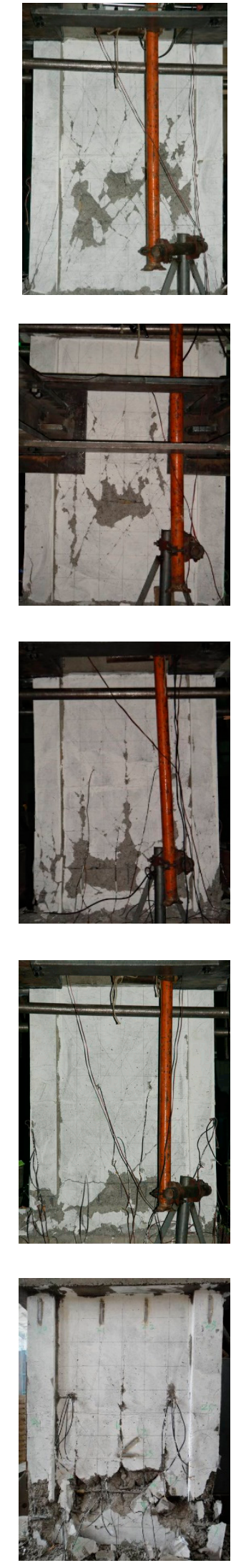

(b) Failure Pattern

Figure 7. Crack Distributions and Failure Patterns of Specimens with Aspect Ratio of 1.5 (a) Crack Distributions at Different Drifts and (b) Photograph of Failure Patterns. 


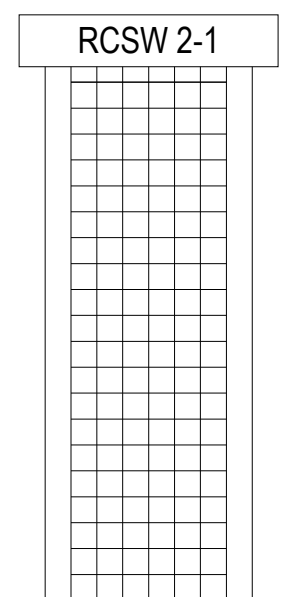

$1 / 1000$

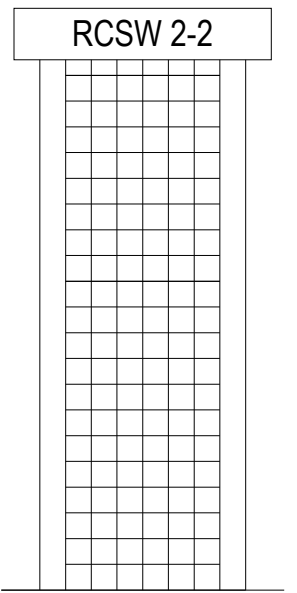

$1 / 1000$

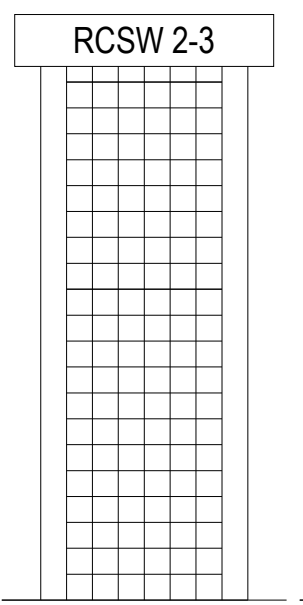

$1 / 1000$

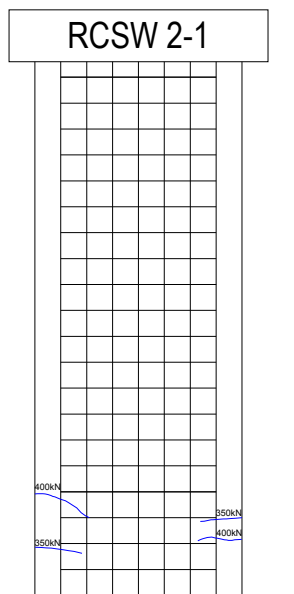

$1 / 300$

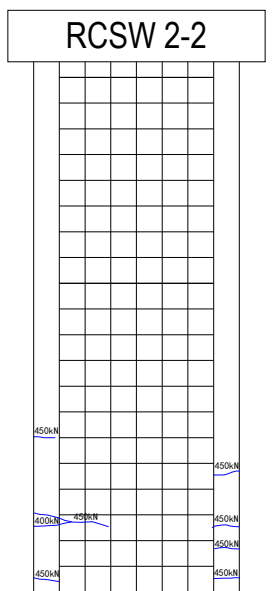

$1 / 300$

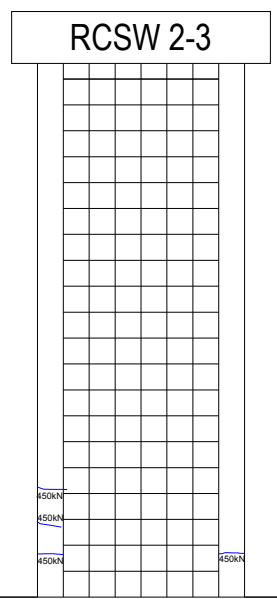

$1 / 300$

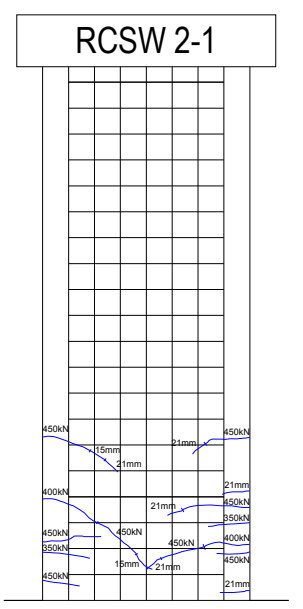

$1 / 100$

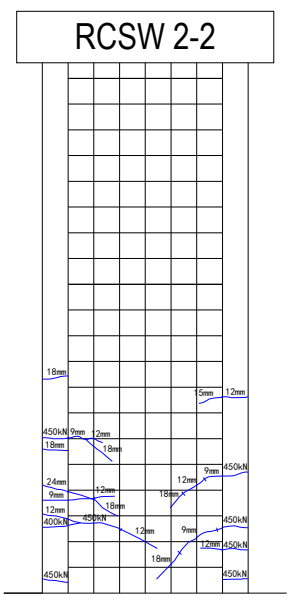

$1 / 100$

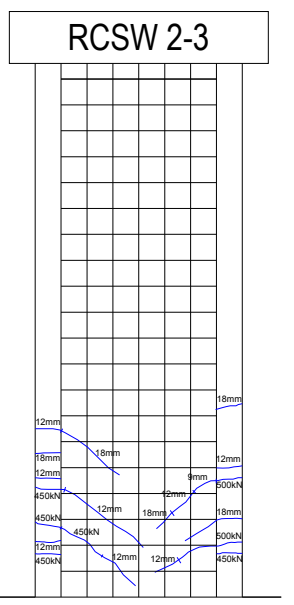

$1 / 100$
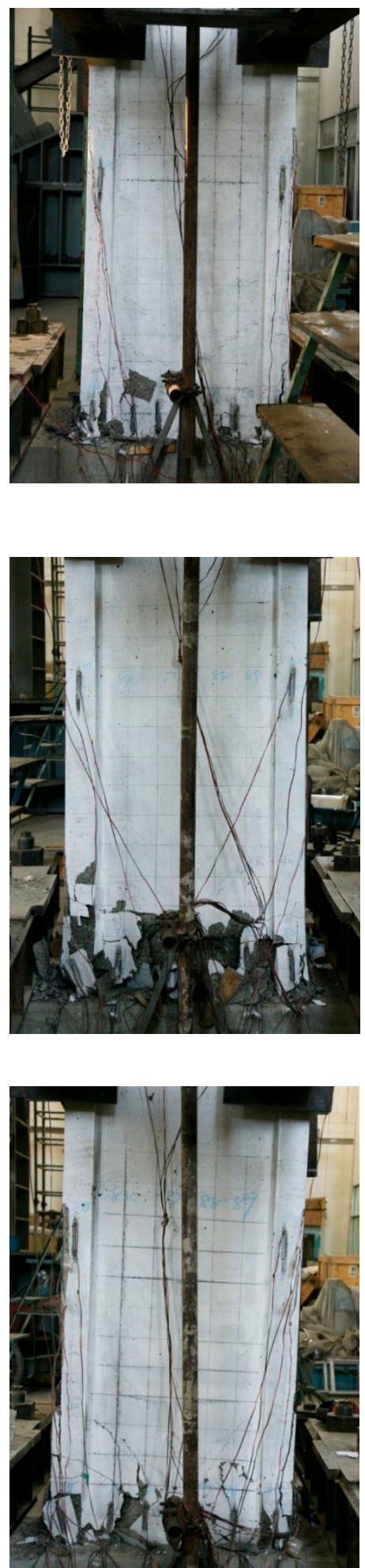

Figure 8. Cont. 


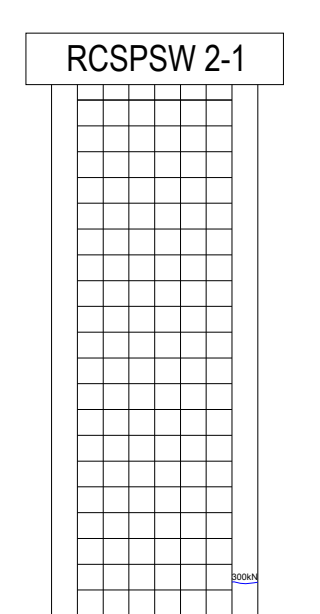

$1 / 1000$

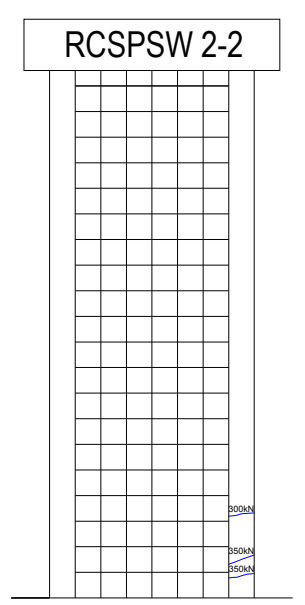

$1 / 1000$

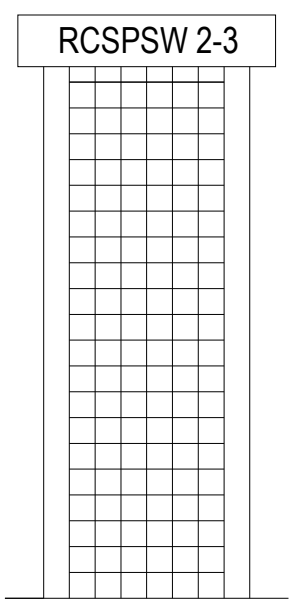

$1 / 1000$

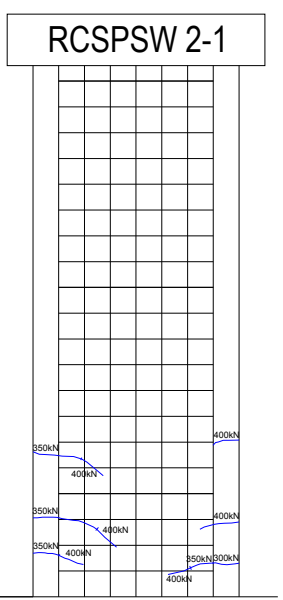

$1 / 300$

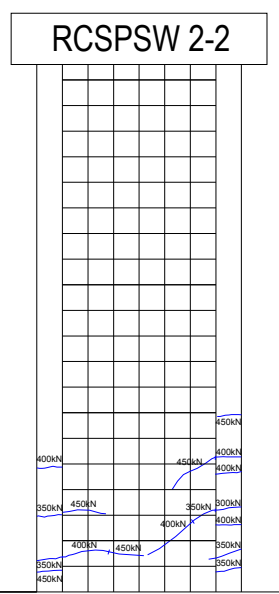

$1 / 300$

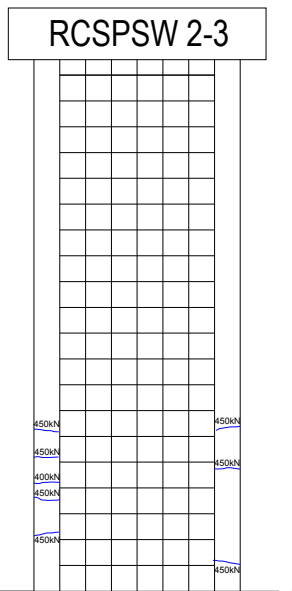

$1 / 300$

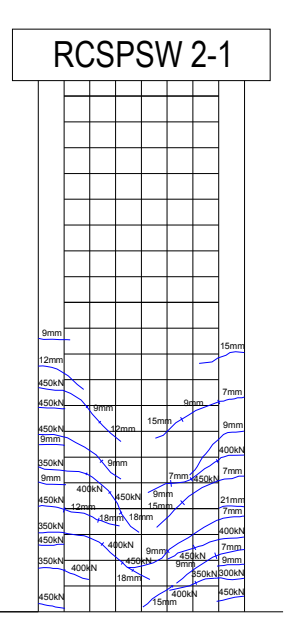

$1 / 100$

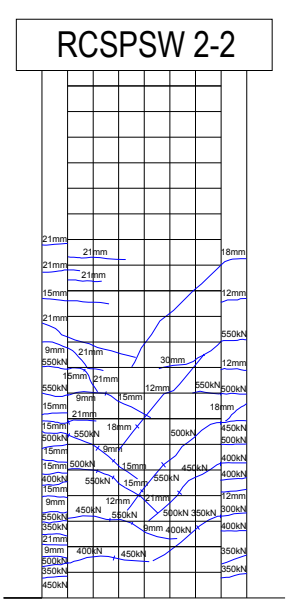

$1 / 100$

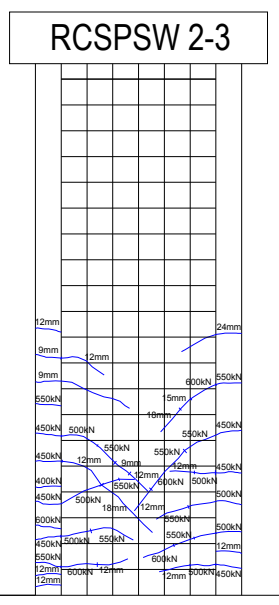

$1 / 100$

(a) Crack Distribution at Different Inter-story Drifts

Figure 8. Crack Distributions and Failure Patterns of Specimens with Aspect Ratio of 2.7 (a) Crack Distributions at Different Drifts and (b) Photograph of Failure Patterns.

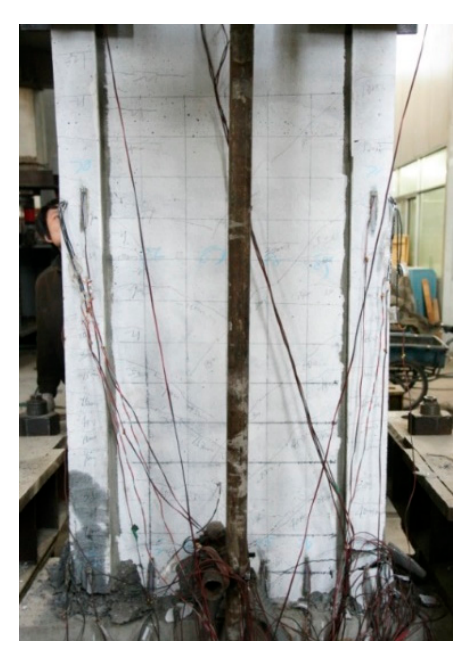

(b) Failure Pattern
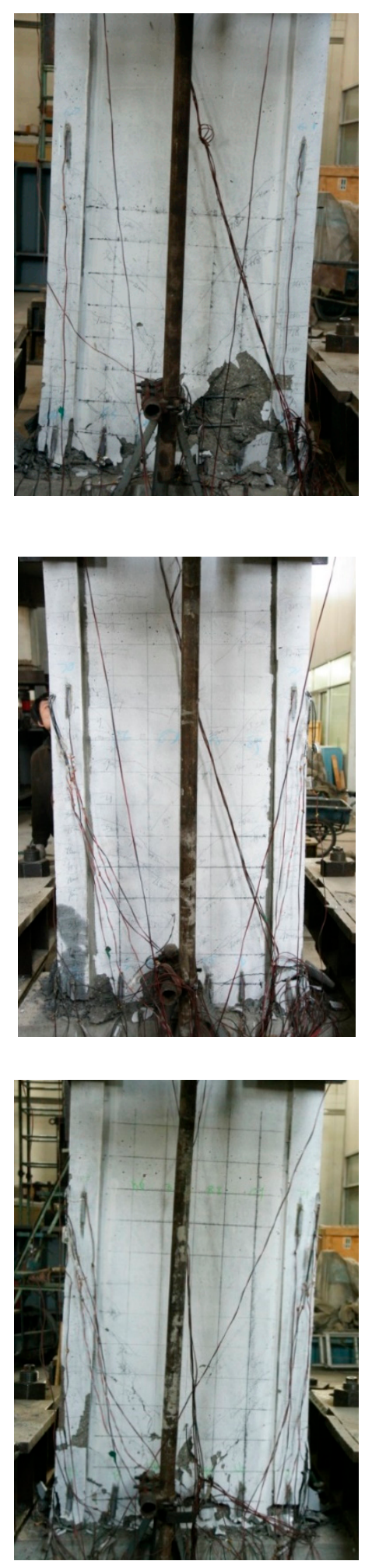

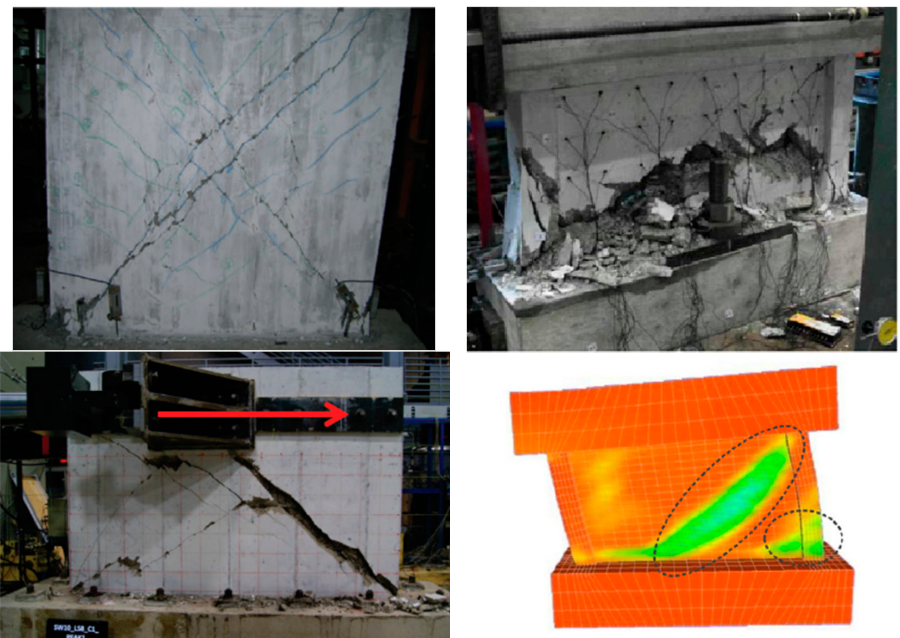

(a) Photograph of Shear Failure Patterns $[1,19,43]$
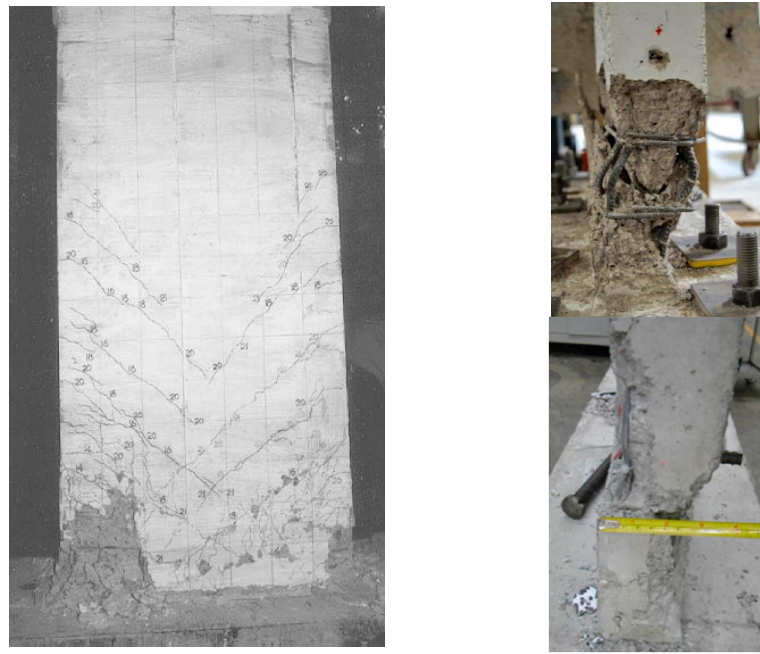

(c) Photograph of Flexure Failure Patterns $[8,9,32]$

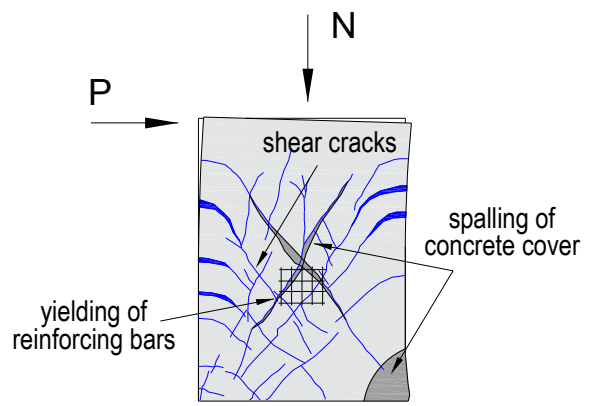

(b) Typical Shear Failure

Characteristics

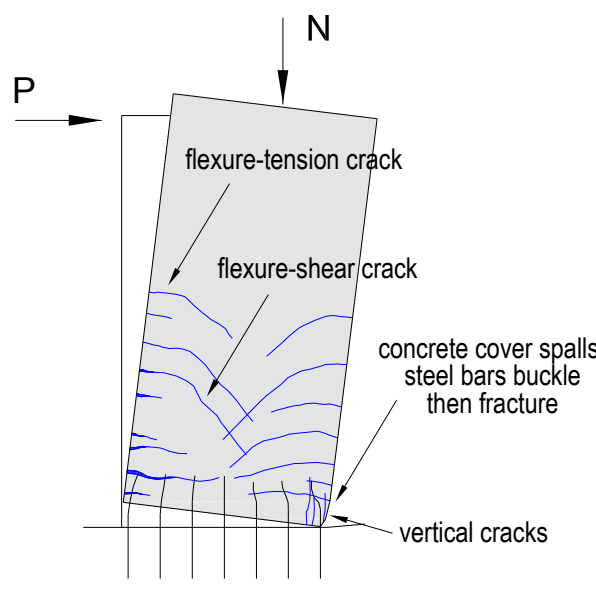

(d) Typical Flexure Failure

Characteristics

Figure 9. Failure Modes of Shear Wall Specimens.

Figure $9 \mathrm{c}$ presents the flexure failure patterns and associated crack distribution excerpt from references [8,9,32]. Flexure-dominant failure starts with horizontal cracks that occur at the wall base on the tensile zone. With the load increasing, new horizontal cracks appear along the wall height and existing cracks gradually expand and propagate inwards to the core of the section. These cracks eventually form an inclined cracking pattern in the web. Upon further loading cycles, vertical reinforcing bars at the wall toe yield and significant inclined flexure-shear cracks form on the lower portion of the wall. Vertical cracks appear at the bottom edge of the compression zone with continuing loading. After the lateral load decreases, the concrete cover at the toe in compression spalls off, finally the failure occurs with the crushing of concrete and buckling of reinforcing bars and steel profiles. The typical flexure failure characteristics include horizontal flexure-tension cracks initiated at wall boundaries, inclined flexure-shear cracks on the wall web, longitudinal reinforcement yielding, vertical cracks and concrete cover spalling at the wall toe, concrete crushing in the compression zone, and buckling of reinforcing bars, as shown in Figure 9d.

In the experimental study that is presented herein, specimens with the aspect ratio of 1.5 exhibited a shear failure mode with significant diagonal cracks appearing in the wall web. As for specimens with the aspect ratio of 2.7, the flexure-dominant failure mode is identified with horizontal cracks 
initiating at the ends, concrete spalling, and tensile fracturing of steel bars. A special characteristic that is observed in RCSPSW specimens is that the embedded steel plate tended to buckle when failure occurred, which was accompanied by severe concrete spalling in the lower portion of the wall. In general, more characteristics of shear failure were observed on the specimens with the decrease of the aspect ratio. A higher axial compression ratio restrained the development of inclined cracks in the web for the reason that the principle tensile stress would be reduced with the increase of the axial load based on experimental observations. Additionally, the "distance" between concrete spalling and wall failure drastically reduces as the axial compression ratio increasing, which results in a more brittle failure mode.

The wall panel in RCSPSW is divided into two halves by the embedded steel plate when compared with conventional RCSW, which results in relatively weaker mechanical collaboration between concrete and steel. It is very important to ensure the effective bonding between two parts to support the engineering application of RCSPSW, although no debonding failure was observed in the quasi-static test. Potential approaches include: (1) using ribbed steel bars with rough surface to increase the mechanical adhesion and friction; (2) specifying sufficient concrete cover to effectively confine steel reinforcement; (3) connecting reinforcement mesh to the embedded steel plate with steel ties, so that the RCSPSW works as a monolithic system; and, (4) adding steel fibers in the concrete to increase the bond strength, as suggested by Dancygier [44] and Harajli [45]. Besides, the use of fiber composite elements is helpful in strengthening the bonding between concrete and steel, and the techniques that were developed by Gattesco [46] using glass fiber reinforced polymer (GFRP) can be deployed.

\subsection{Force-Displacement Responses}

Figure 10 presents the hysteresis curves (blue line) and skeleton curves (red line) for the shear specimens. Significant "pinching" effects were observed in the hysteresis loops of RCSW shear specimens. With the embedment of the steel plate, the hysteresis curves appear in a plumper shape with higher peak lateral load capacities, which indicated that RCSPSW specimens have better seismic performances. Figure 11 shows comparisons among the skeleton curves of all shear specimens. The blue, red, and green lines in Figure 11a,b represent skeleton curves of specimens under the axial compression ratio of $0.33,0.45$, and 0.50 , respectively. The dash and solid lines in Figure 11c show the curves of the RCSW and RCSPSW specimens. It is evident that the use of embedded steel plate significantly increased the lateral load capacity, but a severer and quicker post-peak strength and stiffness degradation was observed in the RCSPSW specimens as compared to RCSW specimens under same axial compression ratios. In terms of the RCSPSW 1-1 specimen, it shows better deformation capability than other RCSPSW specimens, which is attributed to a lower axial compression ratio. Additionally, the positive lateral load re-increased after the strength decay in the previous step, which may result from the hardening of the steel plate.

Figure 12 shows the hysteresis and skeleton curves for flexure specimens. Overall, the RCSW specimens show a S-shaped hysteretic behavior with a "pinching" phenomenon. The hysteresis curves of RCSPSW specimens appear in a full bow shape, which indicates that mixed flexure-shear failure mechanisms exist in the damage progression of flexure specimens. From the results that are presented in Figure 12, it is evident that "fatter" hysteresis loops were obtained for specimens when they were subjected to lower axial compressive loads. Figure 13 presents the comparative results of skeleton curves for different flexure specimens. As compared to the RCSW specimens (dash lines), the RCSPSW specimens (solid lines) show higher lateral load capacities. The skeleton curves with the same color represent specimens subjected to the same axial compressive load. With the increase of the axial compressive load, the peak lateral load increased, but the ultimate lateral displacement decreased. A severer and quicker strength and stiffness degradation was observed for RCSPSW specimens with an axial compression ratio higher than 0.50 . 

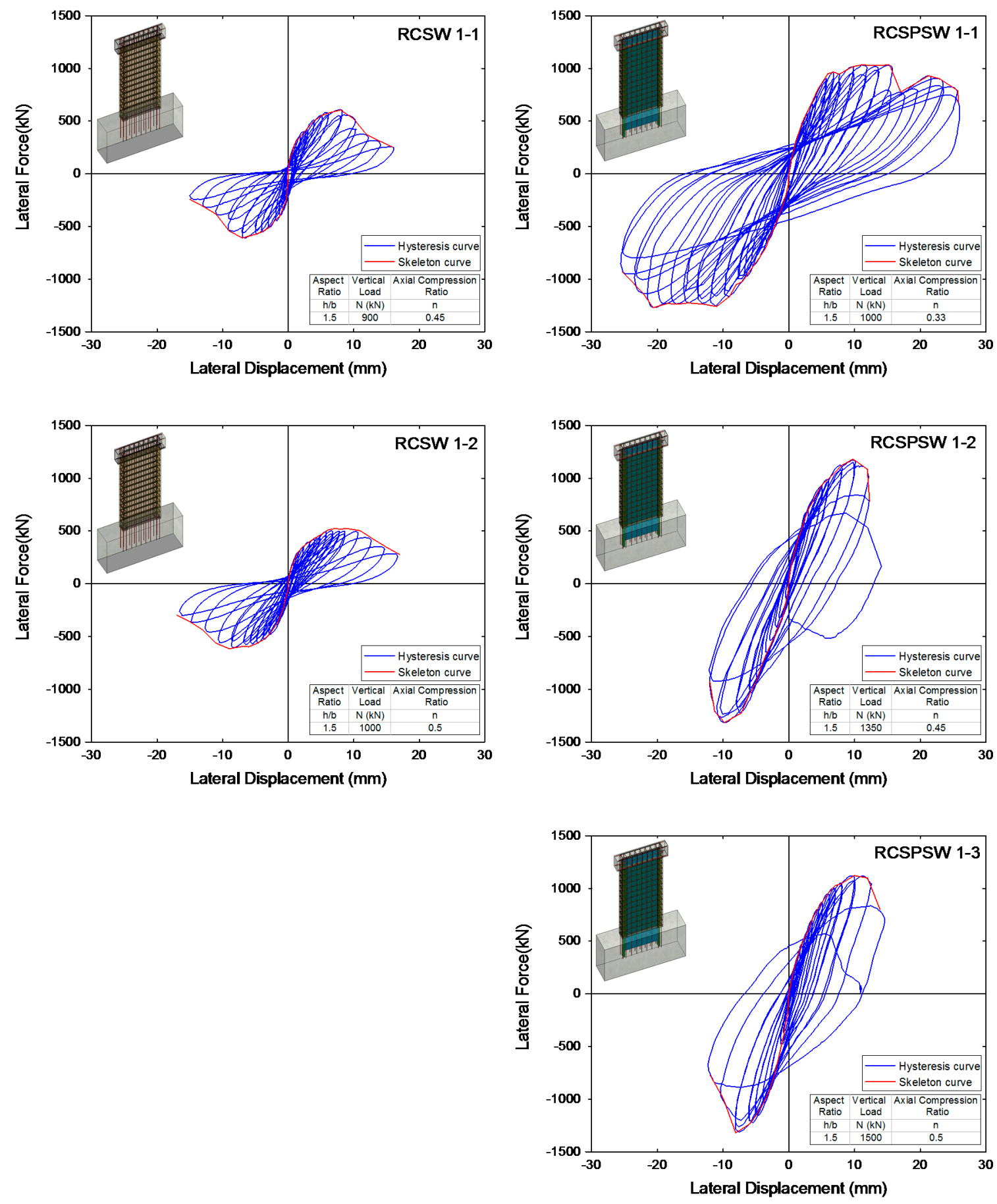

(a) RCSW Specimens

(b) RCSPSW Specimens

Figure 10. Hysteresis and Skeleton Curves for Specimens with Aspect Ratio of 1.5 (a) RCSW Specimens and (b) RCSPSW Specimens. 


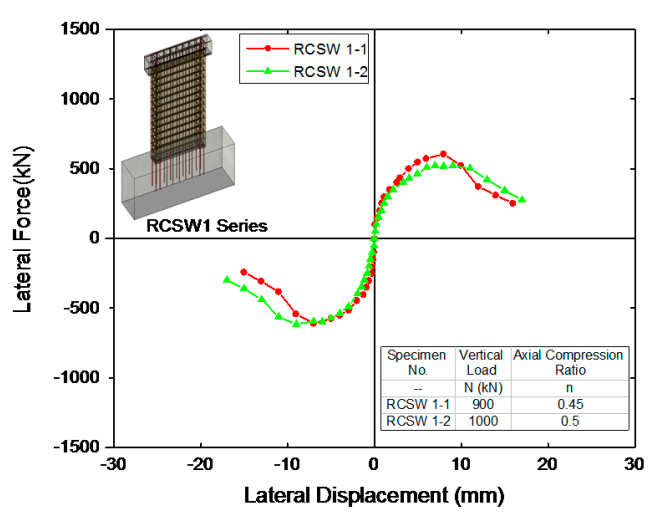

(a) RCSW Shear Specimens

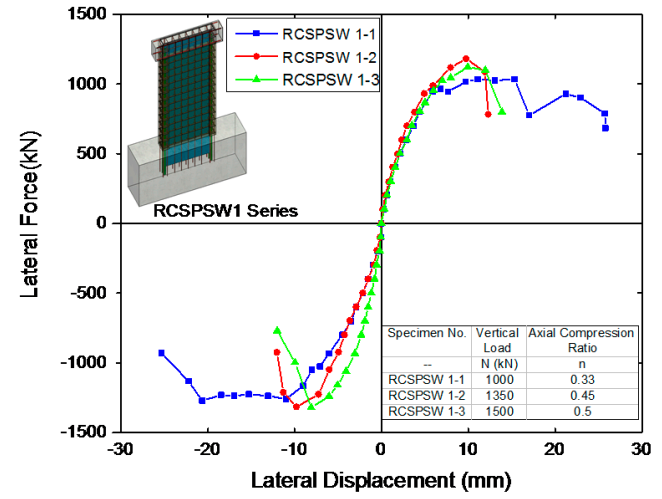

(b) RCSPSW Shear Specimens

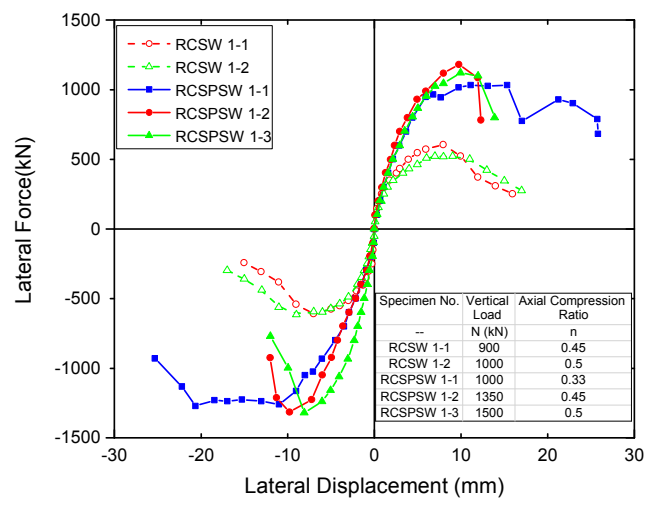

(c) All Shear Specimens

Figure 11. Comparison among the Skeleton Curves for Specimens with Aspect Ratio of 1.5 (a) RCSW Specimens; (b) RCSPSW Specimens; and, (c) All Shear Specimens.

The key characteristics were summarized for all shear wall specimens with considerations of the damage progression and force-displacement responses, although differences do exist among their skeleton curves. Figure 14a shows the skeleton curve of RCSW 1-1 specimen as a representative example, where five critical points are defined, including crack point, yield pint, peak point, failure point, and collapse point. Each critical point represents an event when the specimen's behavior is significantly altered. The crack point corresponds to the load step when the first web inclined shear crack or boundary horizontal flexure-tension crack is observed. The determination of yield point, peak point, and failure point has been described in the previous section. The collapse point indicates the tip of last load cycle if the post-ultimate load capacity $\left(0.85 P_{\max }\right)$ exists. It is worth mentioning that the yield point and failure point in the load-displacement skeleton curve (Figure 14b) can be determined while using alternative approaches. Smarzewski and Pan [47,48] suggested the equivalent elastoplastic line determine the yield displacement with the secant stiffness at two-thirds of the peak lateral load. As for the failure load, Smarzewski and Lim $[47,49]$ recommended the use of $80 \%$ of the peak lateral load, resulting in a relatively larger ultimate displacement as compared to the $0.85 P_{\max }$ defined herein. Based on trial calculations, the yield displacement determined with the approach that was suggested by Smarzewski is slightly lower than the value that was calculated using the Priestley's method, which is adopted in current research work. Therefore, the ductility factors of shear wall specimens determined with Smarzewski's approach would be larger than the values that are presented in this paper. 

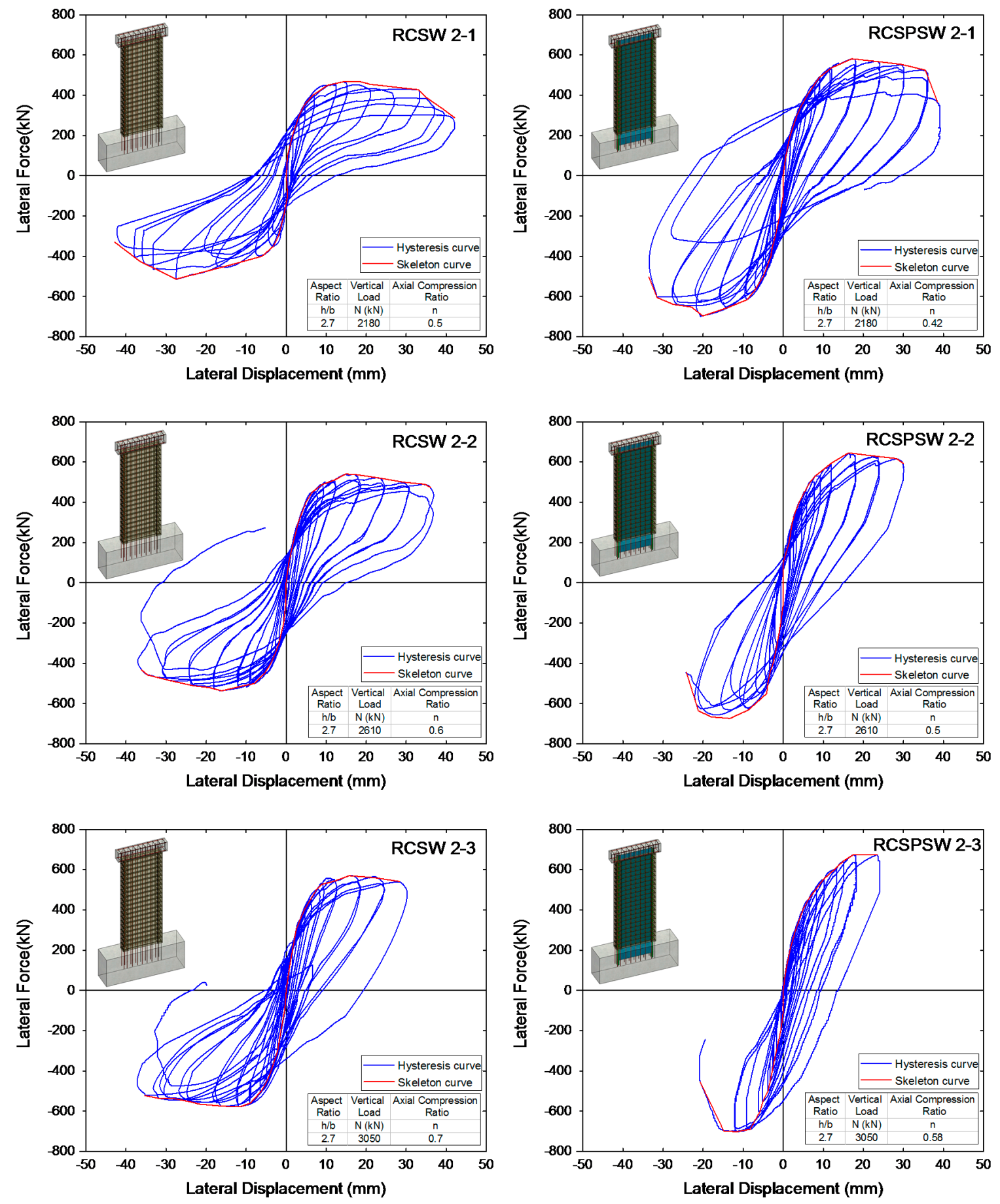

(a) RCSW Specimens

(b) RCSPSW Specimens

Figure 12. Hysteresis and Skeleton Curves for Specimens with Aspect Ratio of 2.7 (a) RCSW Specimens and (b) RCSPSW Specimens. 


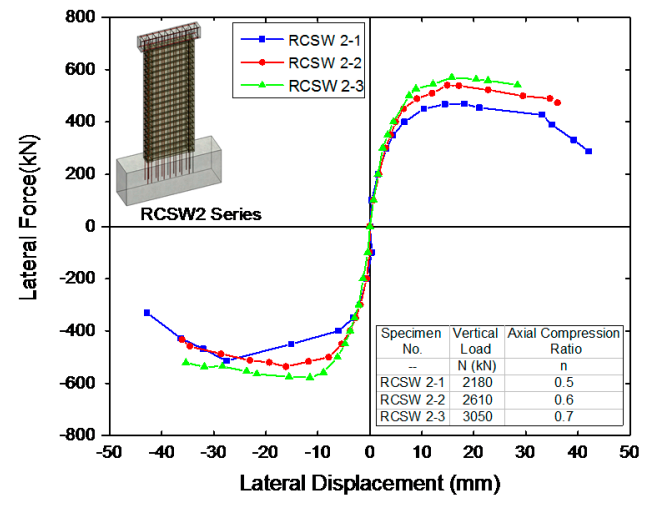

(a) RCSW Specimens

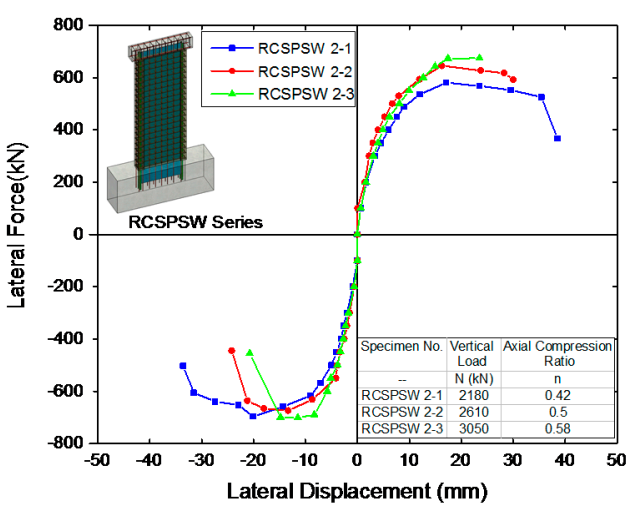

(b) RCSPSW Specimens

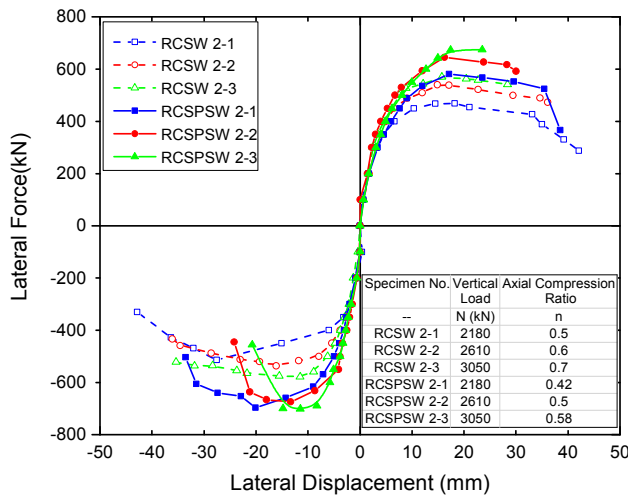

(c) All Flexure Specimens

Figure 13. Comparison among the Skeleton Curves for Specimens with Aspect Ratio of 2.7 (a) RCSW Specimens; (b) RCSPSW Specimens; and, (c) All Flexure Specimens.

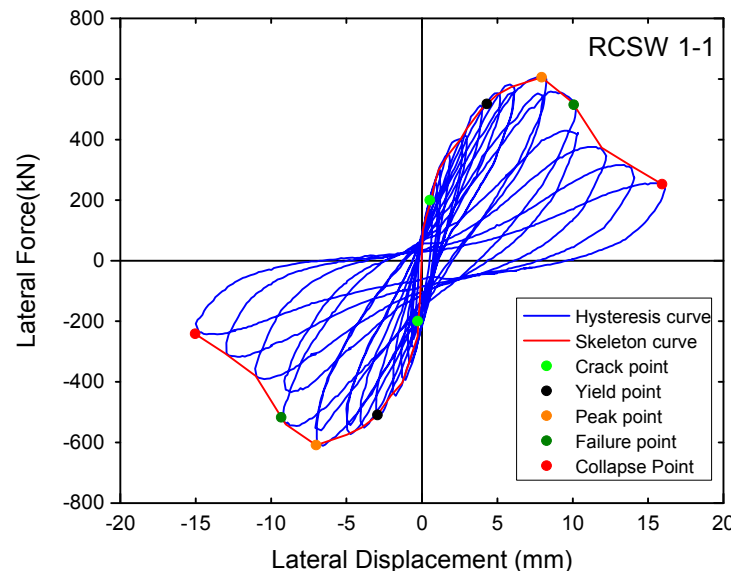

(a) RCSW 1-1 Specimen

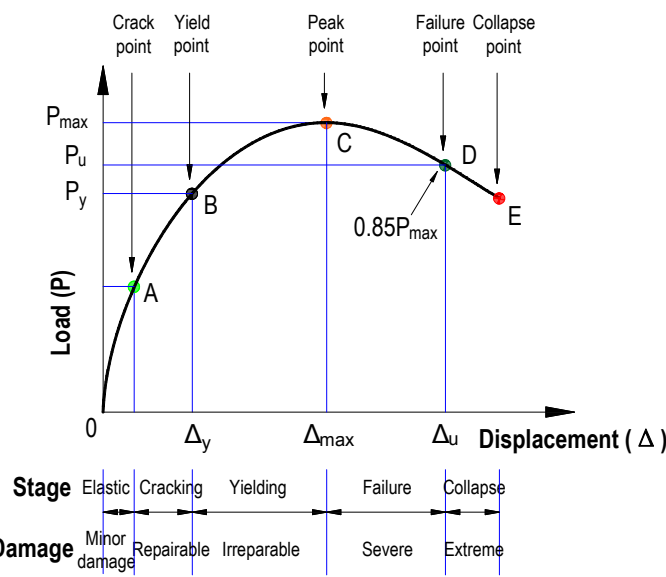

(b) Typical skeleton curve with damage progression

Figure 14. Definition of Critical Points and Working Stages of Shear Wall Specimens.

Based on critical load points, the entire loading procedure was divided into five stages: elastic stage, cracking stage, yielding stage, failure stage, and collapse stage, as shown in Figure 14b. A summary of structural behavior of shear wall specimens in each stage is briefly described, as follows.

(a) Elastic stage (origin to crack point): the specimen keeps intact or minor damage is observed. The structural behavior remains in the elastic range and the load-displacement curve keeps linear. 
(b) Cracking stage (crack point to yield point): as the lateral load increasing, more web inclined cracks and boundary horizontal cracks occur in the shear specimens. As for flexure specimens, the quantity of boundary horizontal cracks increases and some of them diagonally extended to the wall web, forming flexure-shear cracks. Crack width expands, but the damage is repairable. The nonlinearity develops in the load-displacement curve.

(c) Yielding stage (yield point to peak point): web transverse steel bars and boundary longitudinal steel bars are gradually yielding in shear and flexure specimens. The crack distribution becomes denser and the crack width further increases. Vertical cracks and concrete cover spalling occasionally take place in the boundary toe. The damage becomes irreparable in this stage. The lateral load continues increasing, but the stiffness value decreases until the peak load is observed.

(d) Failure stage (peak point to failure point): the lateral load capacity starts to reduce. Significant concrete spalling occurs in boundary toes or web panels. Embedded steel plate tends to buckle out-of-plane. The damage is severe and the cycle load test may end in this stage.

(e) Collapse stage (failure point to collapse point): the damage is extremely severe in this stage. The later load capacity continues reducing until the collapse point occurred.

\subsection{Lateral Load and Dispalceent Capacity}

Table 3 lists lateral load, lateral displacement, and corresponding drift values for the shear specimens at yield point, peak point, and failure point. It is seen that the positive and negative values that were obtained from the cyclic test are asymmetrical, which is also observed in the hysteresis and skeleton curves (Figures 10 and 12). The explanation is when the specimen undergoes damage in one direction; its lateral load capacity is slightly weakened, as it is racked in the opposite direction. The average values are used herein for comparative studies. As compared to RCSW specimens, RCSPSW specimens own approximately $100 \%$ higher yield loads, peak loads, and ultimate loads, proving the efficiency of the embedded steel plate in the improvement of shear load capacities. As for the ultimate displacement, the RCSPSW specimens do not show obvious superiority over RCSW specimens, except for RCSPSW 1-1 under lower axial compression ratio (0.33). In general, RCSPSW shear specimens are capable of withstanding an ultimate drift value of 1.0\% approximately, showing acceptable deformability for design purpose. The last column lists ductility factors for all shear specimens that were determined by Equation (2). The RCSW specimens own relatively higher ductility factors than RCSPSW specimens under the same axial compression ratio.

Table 4 summarizes the lateral load and displacement capacities of flexure specimens. In general, shear wall specimens with a higher aspect ratio show better ductility performances, because the flexural failure mode governs. Similar with shear specimens, the embedment of steel plate is able to increase the lateral load capacities of the flexure specimens. In particular, the peak load capacities of RCSPSW are $20-30 \%$ higher than RCSW under the same axial compressive loads. The RCSW flexure specimens show good deformability with the ultimate drift value of around $1.5 \%$ and the ductility factor higher than 4. As for RCSPSW specimens, the deformability is satisfactory for design purposes when the axial compression ratio is lower than 0.50 (ultimate drift is larger than $1.0 \%$ and the ductility factor is around 4 ). As the axial compression ratio increases to 0.58 , the ductility factor substantially decreases to 2.61 and the ultimate drift is lower than $1.0 \%$.

Figure 15 presents the effects of the axial compression ratio on peak lateral load capacities, ductility factors, and ultimate drift values of all specimens. Blue lines and red lines represent values for shear specimens and flexure specimens; dash and solid lines are results for RCSW specimens and RCSPSW specimens. It is seen from Figure 15a that all the specimens' lateral load capacities increase with the axial compression ratio, except for conventional RCSW shear specimens (RCSW1 series). For the RCSPSW specimens, the ultimate drift decreases with the axial compression ratio. In particular, the value drops below $1 \%$ when it is subjected to the highest axial compressive loads (1500 $\mathrm{kN}$ for shear specimens and 3050 for flexure specimens). The ductility factor generally decreases with the axial compression ratio for RCSPSW specimens, but the trend is not as straightforward as the ultimate drift. 
The relationship between the deformability and axial compression ratio for RCSW specimens (blue lines) is not clear, as seen in Figure 15b,c, but their ultimate drift and ductility factor values are larger than those of the RCSPSW specimens (red lines) when subjected to the axial compression ratio higher than 0.5 .

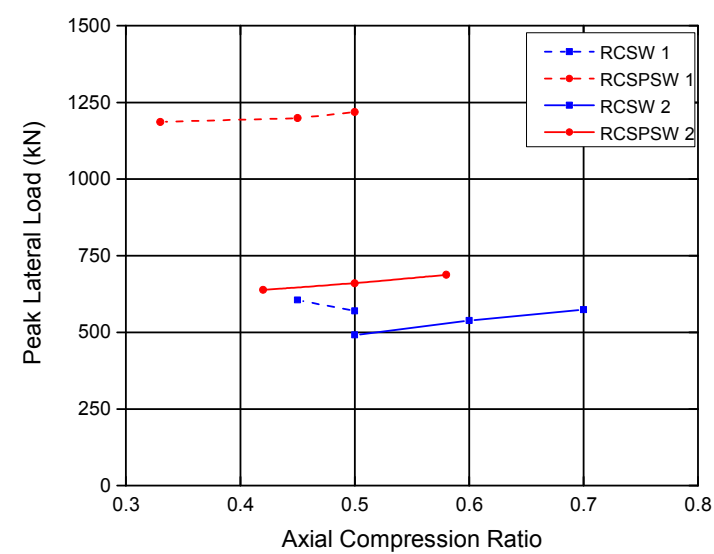

(a) Peak Lateral Load

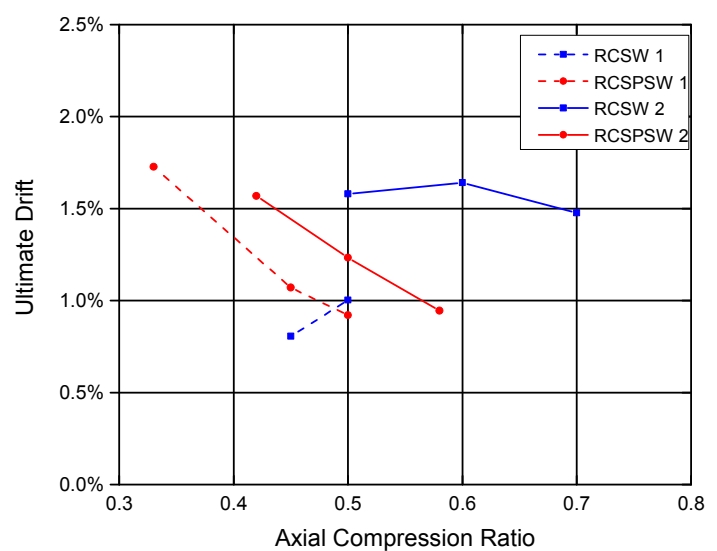

(b) Ultimate Drift

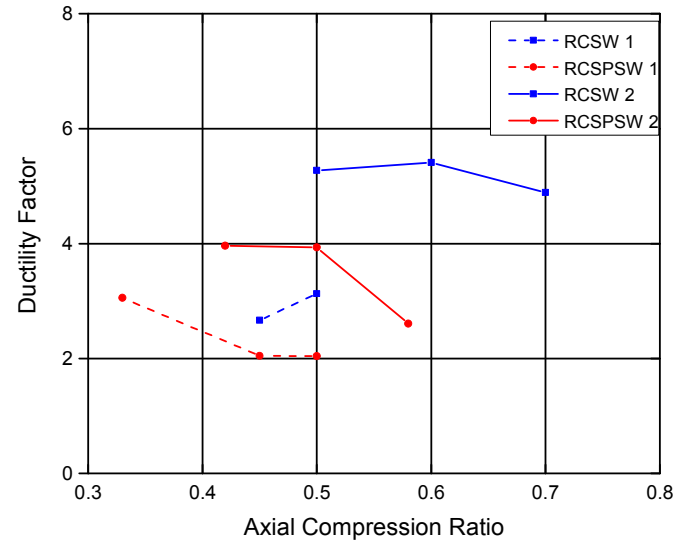

(c) Ductility Factor

Figure 15. Effects of Axial Compression Ratio on (a) Peak Lateral Load; (b) Ultimate Drift; and, (c) Ductility Factor.

It is observed from the experimental test that the RCSPSW specimens show a relatively lower deformability under high axial compression ratios, which could be attributed to the brittleness of high strength concrete. Another explanation is the weak concrete confinement effect on the embedded steel plate due to the small specimen size. The thickness values of the concrete web on both sides are only $40 \mathrm{~mm}$ and $75 \mathrm{~mm}$ for shear and flexure specimens. The concrete cover was easily spalled under higher axial compressive loads, and the embedded steel plate tended to buckle when severe concrete spalling took place. Under such circumstance, the strength and stiffness decay quickly and substantially decay. In addition, shear studs were only used in the footing and the connection between the steel plate and concrete wall web is weak, which exacerbate the spalling and strength reduction. Therefore, it is suggested that the shear wall structural component should be designed with caution when subjected to high axial compressive loads and an upper limit of axial compression ratio (0.5) should be set for RCSPSW. Besides, shear studs or steel ties should be used to strengthen the connection between the steel plate and concrete on both sides. Additionally, a higher transverse reinforcement ratio is recommended for further improving the concrete confinement effect. It is worth mentioning that the wall is much thicker in the practical design of high-rise buildings. Thus, the confinement effect and deformability of RCSPSW in future applications could be better than the experimental observations. 
Table 3. Lateral Load and Displacement Capacity of Shear Specimens.

\begin{tabular}{|c|c|c|c|c|c|c|c|c|c|c|c|}
\hline \multirow{2}{*}{$\begin{array}{c}\text { Specimen } \\
\text { No. }\end{array}$} & \multirow{2}{*}{ Direction } & \multicolumn{3}{|c|}{ Yield } & \multicolumn{3}{|c|}{ Peak } & \multicolumn{3}{|c|}{ Ultimate } & \multirow{2}{*}{$\begin{array}{c}\begin{array}{c}\text { Ductility } \\
\text { Factor }\end{array} \\
\Delta=\Delta_{\mathrm{u}} / \Delta_{\mathrm{y}}\end{array}$} \\
\hline & & $P_{\mathrm{y}}(\mathrm{kN})$ & $\Delta_{\mathrm{y}}(\mathrm{mm})$ & Drift $(\%)$ & $P_{\max }(\mathrm{kN})$ & $\Delta_{\max }(\mathrm{mm})$ & Drift $(\%)$ & $P_{\mathrm{u}}(\mathrm{kN})$ & $\Delta_{\mathrm{u}}(\mathrm{mm})$ & Drift $(\%)$ & \\
\hline \multirow{3}{*}{ RCSW 1-1 } & + & 517 & 4.3 & $0.36 \%$ & 604 & 8.0 & $0.67 \%$ & 513 & 10.1 & $0.84 \%$ & 2.34 \\
\hline & - & 509 & 2.9 & $0.25 \%$ & 606 & 7.0 & $0.58 \%$ & 515 & 9.3 & $0.77 \%$ & 3.15 \\
\hline & Average & 513 & 3.6 & $0.30 \%$ & 605 & 7.5 & $0.63 \%$ & 514 & 9.7 & $0.81 \%$ & 2.67 \\
\hline \multirow{3}{*}{ RCSW 1-2 } & + & 437 & 4.1 & $0.35 \%$ & 522 & 9.0 & $0.75 \%$ & 444 & 12.4 & $1.04 \%$ & 3.00 \\
\hline & - & 516 & 3.5 & $0.30 \%$ & 617 & 8.9 & $0.74 \%$ & 524 & 11.6 & $0.97 \%$ & 3.28 \\
\hline & Average & 477 & 3.8 & $0.32 \%$ & 570 & 8.9 & $0.74 \%$ & 484 & 12.0 & $1.00 \%$ & 3.13 \\
\hline \multirow{3}{*}{$\begin{array}{c}\text { RCSPSW } \\
1-1\end{array}$} & + & 941 & 5.8 & $0.49 \%$ & 1070 & 11.2 & $0.93 \%$ & 910 & 17.0 & $1.42 \%$ & 2.92 \\
\hline & - & 1043 & 7.7 & $0.64 \%$ & 1301 & 10.9 & $0.91 \%$ & 1106 & 24.4 & $2.04 \%$ & 3.16 \\
\hline & Average & 992 & 6.8 & $0.57 \%$ & 1186 & 11.0 & $0.92 \%$ & 1008 & 20.7 & $1.73 \%$ & 3.05 \\
\hline \multirow{3}{*}{$\begin{array}{c}\text { RCSPSW } \\
1-2\end{array}$} & + & 983 & 5.9 & $0.49 \%$ & 1156 & 9.7 & $0.81 \%$ & 983 & 13.9 & $1.16 \%$ & 2.37 \\
\hline & - & 1109 & 6.7 & $0.56 \%$ & 1242 & 9.8 & $0.82 \%$ & 1056 & 11.8 & $0.99 \%$ & 1.77 \\
\hline & Average & 1046 & 6.3 & $0.52 \%$ & 1199 & 9.8 & $0.81 \%$ & 1019 & 12.9 & $1.07 \%$ & 2.05 \\
\hline \multirow{3}{*}{$\begin{array}{c}\text { RCSPSW } \\
1-3\end{array}$} & + & 978 & 6.4 & $0.53 \%$ & 1117 & 10.0 & $0.83 \%$ & 949 & 12.9 & $1.07 \%$ & 2.03 \\
\hline & - & 1102 & 4.5 & $0.37 \%$ & 1318 & 8.1 & $0.67 \%$ & 1120 & 9.2 & $0.77 \%$ & 2.06 \\
\hline & Average & 1040 & 5.4 & $0.45 \%$ & 1218 & 9.0 & $0.75 \%$ & 1035 & 11.1 & $0.92 \%$ & 2.04 \\
\hline
\end{tabular}


Table 4. Lateral Load and Displacement Capacity of Flexure Specimens.

\begin{tabular}{|c|c|c|c|c|c|c|c|c|c|c|c|}
\hline \multirow{2}{*}{$\begin{array}{l}\text { Specimen } \\
\text { No. }\end{array}$} & \multirow[t]{2}{*}{ Direction } & \multicolumn{3}{|c|}{ Yield } & \multicolumn{3}{|c|}{ Peak } & \multicolumn{3}{|c|}{ Ultimate } & \multirow{2}{*}{$\begin{array}{c}\begin{array}{c}\text { Ductility } \\
\text { Factor }\end{array} \\
\Delta=\Delta_{\mathrm{u}} / \Delta_{\mathrm{y}}\end{array}$} \\
\hline & & $P_{\mathrm{y}}(\mathrm{kN})$ & $\Delta_{\mathrm{y}}(\mathrm{mm})$ & Drift (\%) & $P_{\max }(\mathbf{k N})$ & $\Delta_{\max }(\mathrm{mm})$ & Drift (\%) & $P_{\mathrm{u}}(\mathrm{kN})$ & $\Delta_{\mathbf{u}}(\mathbf{m m})$ & Drift (\%) & \\
\hline \multirow{3}{*}{ RCSW 2-1 } & + & 386 & 6.0 & $0.28 \%$ & 469 & 18.2 & $0.84 \%$ & 398 & 32.9 & $1.52 \%$ & 5.45 \\
\hline & - & 405 & 6.9 & $0.32 \%$ & 514 & 27.5 & $1.28 \%$ & 437 & 35.4 & $1.64 \%$ & 5.12 \\
\hline & Average & 396 & 6.5 & $0.30 \%$ & 491 & 22.9 & $1.06 \%$ & 418 & 34.2 & $1.58 \%$ & 5.27 \\
\hline \multirow{3}{*}{ RCSW 2-2 } & + & 455 & 6.8 & $0.32 \%$ & 540 & 14.9 & $0.69 \%$ & 473 & 36.1 & $1.67 \%$ & 5.29 \\
\hline & - & 468 & 6.3 & $0.29 \%$ & 536 & 16.1 & $0.75 \%$ & 456 & 34.8 & $1.61 \%$ & 5.54 \\
\hline & Average & 461 & 6.6 & $0.30 \%$ & 538 & 15.5 & $0.72 \%$ & 464 & 35.5 & $1.64 \%$ & 5.41 \\
\hline \multirow{3}{*}{ RCSW 2-3 } & + & 487 & 7.2 & $0.33 \%$ & 570 & 15.8 & $0.73 \%$ & 541 & 28.4 & $1.31 \%$ & 3.97 \\
\hline & - & 488 & 5.9 & $0.27 \%$ & 578 & 11.5 & $0.53 \%$ & 522 & 35.4 & $1.64 \%$ & 6.01 \\
\hline & Average & 488 & 6.5 & $0.30 \%$ & 574 & 13.6 & $0.63 \%$ & 531 & 31.9 & $1.48 \%$ & 4.89 \\
\hline \multirow{3}{*}{$\begin{array}{c}\text { RCSPSW } \\
2-1\end{array}$} & + & 497 & 9.6 & $0.44 \%$ & 581 & 17.1 & $0.79 \%$ & 493 & 36.1 & $1.67 \%$ & 3.78 \\
\hline & - & 581 & 7.6 & $0.35 \%$ & 697 & 20.1 & $0.93 \%$ & 592 & 31.7 & $1.47 \%$ & 4.19 \\
\hline & Average & 539 & 8.6 & $0.40 \%$ & 639 & 18.6 & $0.86 \%$ & 543 & 33.9 & $1.57 \%$ & 3.96 \\
\hline \multirow{3}{*}{$\begin{array}{c}\text { RCSPSW } \\
2-2\end{array}$} & + & 536 & 8.4 & $0.39 \%$ & 646 & 16.3 & $0.75 \%$ & 592 & 30.0 & $1.39 \%$ & 3.59 \\
\hline & - & 569 & 5.2 & $0.24 \%$ & 674 & 13.3 & $0.62 \%$ & 573 & 23.3 & $1.08 \%$ & 4.48 \\
\hline & Average & 553 & 6.8 & $0.31 \%$ & 660 & 14.8 & $0.68 \%$ & 583 & 26.7 & $1.23 \%$ & 3.93 \\
\hline \multirow{3}{*}{$\begin{array}{c}\text { RCSPSW } \\
2-3\end{array}$} & + & 560 & 10.5 & $0.48 \%$ & 674 & 15.0 & $0.69 \%$ & 561 & 23.5 & $1.09 \%$ & 2.25 \\
\hline & - & 581 & 5.2 & $0.24 \%$ & 701 & 11.5 & $0.53 \%$ & 539 & 17.3 & $0.80 \%$ & 3.33 \\
\hline & Average & 571 & 7.8 & $0.36 \%$ & 688 & 13.2 & $0.61 \%$ & 550 & 20.4 & $0.94 \%$ & 2.61 \\
\hline
\end{tabular}




\subsection{Energy Dissipation Ability}

The EVD coefficients for all specimens were calculated with Equation (3) to compare their energy dissipation abilities. Table 5 lists hysteresis loop areas and EVD coefficients of all the test specimens for test cycles at the peak lateral load (peak point).

Table 5. Equivalent Viscous Damping (EVD) Coefficients of All Specimens.

\begin{tabular}{cccc}
\hline Specimen Batch & Specimen No. & Hysteresis Loop Area (kN·mm) & EVD Coefficient \\
\hline \multirow{3}{*}{ Shear Specimens } & RCSW 1-1 & 3518 & 0.123 \\
\cline { 2 - 4 } & RCSW 1-2 & 3513 & 0.109 \\
\cline { 2 - 4 } & RCSPSW 1-1 & 11600 & 0.129 \\
\cline { 2 - 4 } & RCSPSW 1-2 & 11949 & 0.156 \\
\hline \multirow{3}{*}{ Flexure Specimens } & RCSPSW 1-3 & 10604 & 0.157 \\
\cline { 2 - 4 } & RCSW 2-1 & 12064 & 0.212 \\
\cline { 2 - 4 } & RCSW 2-2 & 10395 & 0.184 \\
\cline { 2 - 4 } & RCSW 2-3 & 11790 & 0.189 \\
\cline { 2 - 4 } & RCSPSW 2-1 & 18044 & 0.202 \\
\cline { 2 - 4 } & RCSPSW 2-2 & 13442 & 0.207 \\
\hline
\end{tabular}

In general, the energy dissipation capacities that were found in shear mode of failure are weaker than those in flexure-controlled failure, and the embedment of steel plate effectively improves the energy dissipation ability of RCSW. For the RCSPSW specimens, the hysteresis loop area decreases with the increase of axial compressive load. Specifically, for the RCSPSW 2-3 specimen that was subjected to the highest axial compressive load $(3050 \mathrm{kN})$, its EVD coefficient is significantly lower than other RCSPSW flexure specimens.

\section{Design Models for RCSPSW}

\subsection{Shear Strength Model}

The form of the shear strength equation refers to the design model that was suggested by Chinese Code for Design of Composite Structures [50], given as:

$$
V=V_{\mathrm{c}}+V_{\mathrm{s}}+V_{\mathrm{a}}+V_{\mathrm{p}}
$$

where the shear strength, $V$, is contributed by four components: concrete shear-resisting component, $V_{\mathrm{c}}$, horizontal reinforcement shear-resisting component, $V_{\mathrm{s}}$, boundary steel profiles shear-resisting component, $V_{\mathrm{a}}$, and embedded steel plate shear-resisting component, $V_{\mathrm{p}}$. Equation (5) provides the expressions for different shear strength components.

$$
\left\{\begin{array}{l}
V_{\mathrm{c}}=0.67 f_{\mathrm{t}} b_{\mathrm{w}} h_{0}+0.2 N \frac{A_{\mathrm{w}}}{A} \\
V_{\mathrm{s}}=f_{\mathrm{yh}} \frac{A_{\mathrm{sh}}}{\mathrm{s}} h \\
V_{\mathrm{a}}=\frac{0.3}{\lambda} f_{\mathrm{a}} A_{\mathrm{a}} \\
V_{\mathrm{p}}=\frac{0.6}{\lambda-0.5} f_{\mathrm{p}} A_{\mathrm{p}}
\end{array}\right.
$$

where $f_{\mathrm{t}}$ is concrete tensile strength; $b_{\mathrm{w}}$ is the web width; $h_{\mathrm{w}}$ is the web depth; $h$ and $h_{0}$ are the depth and effective depth of the shear wall section; $A_{\mathrm{w}}$ and $A$ represent the area of concrete web and entire section, respectively; $N$ indicates the axial compressive load, $N \leq 0.2 f_{\mathrm{c}} b_{\mathrm{w}} h_{\mathrm{w}} ; f_{\mathrm{yh}}, f_{a}$, and $f_{\mathrm{p}}$ mean the yield strength of transverse web reinforcement, boundary I-shape steel profiles, and embedded 
steel plate; $A_{\mathrm{yh}}, A_{\mathrm{a}}$, and $A_{\mathrm{p}}$ denote the area of those three components; $s$ is the spacing of transverse reinforcement; and, $\lambda$ is the aspect ratio.

Table 6 summarizes shear strength capacities that were measured from the quasi-static cyclic load test and calculated by shear strength models. Note that the measured characteristic concrete strength values were used in the calculation. It is seen from Table 6 that design models provide 10-15 percent conservative shear strength capacity values for RCSW specimens as compared to the test results. In terms of RCSPSW specimens, shear strength capacities that are estimated by design models are very close to the average experimental data, but 5-10 percent lower shear strength values were observed in the positive direction. A correction factor, $k_{\mathrm{s}}$, for design models is taken as 0.9 to determine the shear strength capacity in order to achieve a reasonable degree of conservatism. Figure 16a presents the comparison of design strength capacities and experimental results for the shear specimens. Dash red line shows the design values determined by the modified design model with the correction factor. It is evident that the modified design shear capacities are generally larger than the test values in both positive and negative directions, and a reasonable degree of conservatism (approximate 10-20 percent) is obtained by using the shear correction factor.

Table 6. Comparisons of Experimental and Design Strength Capacities for Shear Specimens.

\begin{tabular}{|c|c|c|c|c|c|c|c|}
\hline \multirow{2}{*}{ Specimen No. } & \multicolumn{3}{|c|}{ Experimental Results (kN) } & \multirow{2}{*}{$\begin{array}{l}\text { Design Model } \\
\text { Results (kN) }\end{array}$} & \multicolumn{3}{|c|}{ Differences } \\
\hline & Positive & Negative & Average & & Positive & Negative & Average \\
\hline RCSW 1-1 & 604 & 606 & 605 & \multirow{2}{*}{512} & $15 \%$ & $16 \%$ & $15 \%$ \\
\hline RCSW 1-2 & 522 & 617 & 570 & & $2 \%$ & $17 \%$ & $9 \%$ \\
\hline RCSPSW 1-1 & 1070 & 1301 & 1186 & 1199 & $-12 \%$ & $8 \%$ & $-2 \%$ \\
\hline RCSPSW 1-2 & 1156 & 1242 & 1199 & \multirow{2}{*}{1213} & $-5 \%$ & $2 \%$ & $-1 \%$ \\
\hline RCSPSW 1-3 & 1117 & 1318 & 1218 & & $-9 \%$ & $8 \%$ & $0 \%$ \\
\hline
\end{tabular}

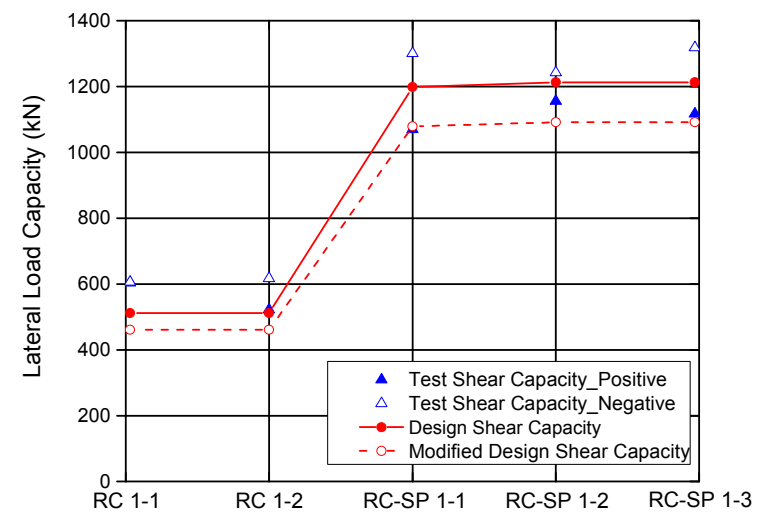

(a) Shear Specimens

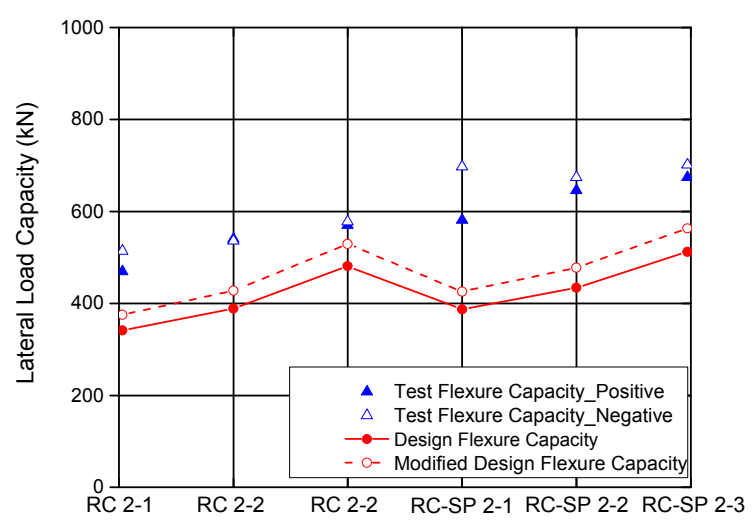

(b) Flexure Specimens

Figure 16. Comparisons of Design Strength Capacities and Experimental Results for Shear Specimens and Flexure Specimens.

According to Equation (5), the shear strength capacities contributed by reinforced concrete $\left(V_{\mathrm{c}}+V_{\mathrm{s}}\right)$, I-shape steel profiles $\left(V_{\mathrm{a}}\right)$, and the steel plate $\left(V_{\mathrm{p}}\right)$ were quantified and are summarized in Table 7. It is seen that the embedded steel plate takes up approximately 50 percent of the design shear strength capacity. For comparisons, shear strength provided values by each component in the cyclic test were inferred from strain gauge readings. Figure 17a shows the strain gauge arrangement in boundary I-shape steel profiles and the embedded steel plate. Shear strength that was provided 
by boundary I-shape steel profiles was calculated based on strain values of SG16-SG19 by following Equation (6).

$$
V_{\mathrm{a}}=\frac{W_{\mathrm{a}} E_{\mathrm{a}}\left|\frac{\varepsilon_{\mathrm{SG} 16}+\varepsilon_{\mathrm{SG} 17}}{2}-\frac{\varepsilon_{\mathrm{SG} 18}+\varepsilon_{\mathrm{SG} 19}}{2}\right| / 2}{H}
$$

where $E_{\mathrm{a}}$ is measured Young's Modulus of I-shape steels; $W_{\mathrm{a}}$ is the section modulus; and, $H$ is the height of shear specimens.

Table 7. Design Strength Capacities Contributed by Different Components in RCSPSW.

\begin{tabular}{ccccc}
\hline \multirow{2}{*}{ Specimen No. } & \multicolumn{4}{c}{ Shear Strength Capacities (kN) } \\
\cline { 2 - 5 } & Reinforced Concrete & I-Shape Steels & Steel Plate & Total \\
\hline RCSPSW 1-1 & $515(43 \%)$ & $116(10 \%)$ & $568(47 \%)$ & 1199 \\
\hline RCSPSW 1-2 & $529(44 \%)$ & $116(10 \%)$ & $568(46 \%)$ & 1213 \\
\hline RCSPSW 1-3 & $529(44 \%)$ & $116(10 \%)$ & $568(46 \%)$ & 1213 \\
\hline
\end{tabular}

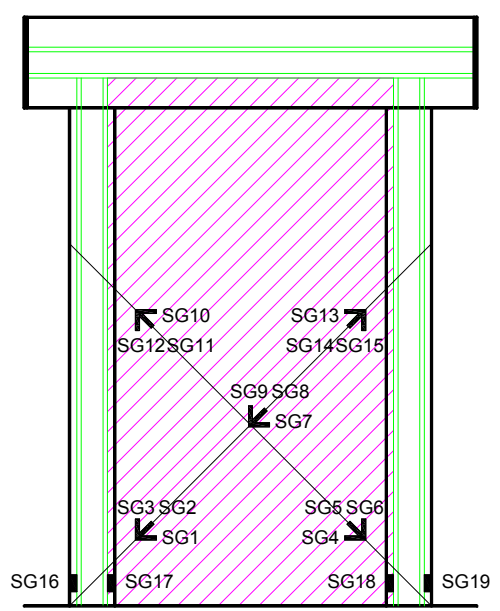

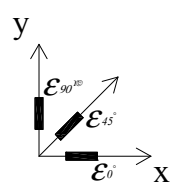
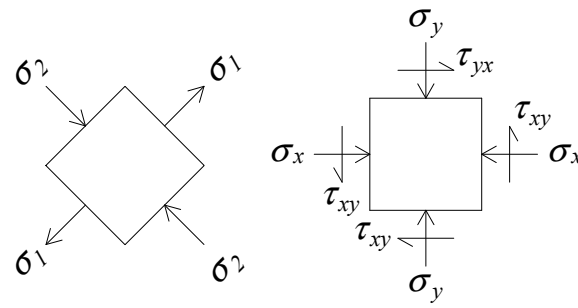

(a) Strain Gauges in Steel Plate (b) Strain

Rosette (c) Principle Stress

(d) Stress

Figure 17. Shear Strength of I-shape Steels and Steel Plate Inferred from Strain Gauge Readings (a) Strain Gauge Arrangement in the I-shape Steels and Steel Plate; (b) Strain Rosette; (c) Principle Stress State; and, (d) Required Stress State.

Strain rosettes were attached on the embedded steel plate. Strain values of SG7, SG8, and SG9 are recorded and used to infer principle stress state and horizontal shear stress state and further determine the shear strength by using Equation (7).

$$
\left\{\begin{array}{c}
\left\{\begin{array}{c}
\sigma_{1} \\
\sigma_{2}
\end{array}\right\}=\frac{E\left(\varepsilon_{00}+\varepsilon_{90}\right)}{2(1-v)} \pm \frac{\sqrt{2} E_{\mathrm{p}}}{2(1+v)} \sqrt{\left(\varepsilon_{0^{0}}-\varepsilon_{45^{0}}\right)^{2}+\left(\varepsilon_{45^{0}}-\varepsilon_{90^{0}}\right)^{2}} \\
V_{\mathrm{p}}=A_{\mathrm{s}} \tau_{\mathrm{yx}}
\end{array}\right.
$$

where $\varepsilon_{0^{0}}, \varepsilon_{45^{0}}$, and $\varepsilon_{90^{0}}$ represent strain rosette readings; $E_{\mathrm{p}}$ is the Young's Modulus of steel plate; $v$ is the Poisson's ratio; $A_{s}$ is the area of steel plate; and, $\tau_{\mathrm{yx}}$ is the horizontal stress. Note that the shear strength of steel plate is considered to be unchanged after yielding, and shear-resisting component of reinforced concrete is taken as the lateral load strength of RCSW specimens under the same axial compression ratios.

Figure 18 shows the shear-resisting strength that was contributed by different components in the cyclic load test. The blue line, red line, and green line show the capacity trend of reinforced concrete, 
I-shape steel profiles, and steel plate. The magenta line presents the experimental skeleton curve for a comparative study. It is observed that the shear strength of all the components increases in the elastic stage. When the specimen goes to the crack stage, the strength increase of reinforced concrete component becomes slower. Moreover, the shear strength of the reinforced concrete component decreases before the specimen reaches the peak lateral load, while the steel plate's strength continues increasing. At the failure point, the summation of shear-resisting strength that is provided by different components is close to the value that is presented in the skeleton curve, showing that the calculation of different components' shear strength is reliable.

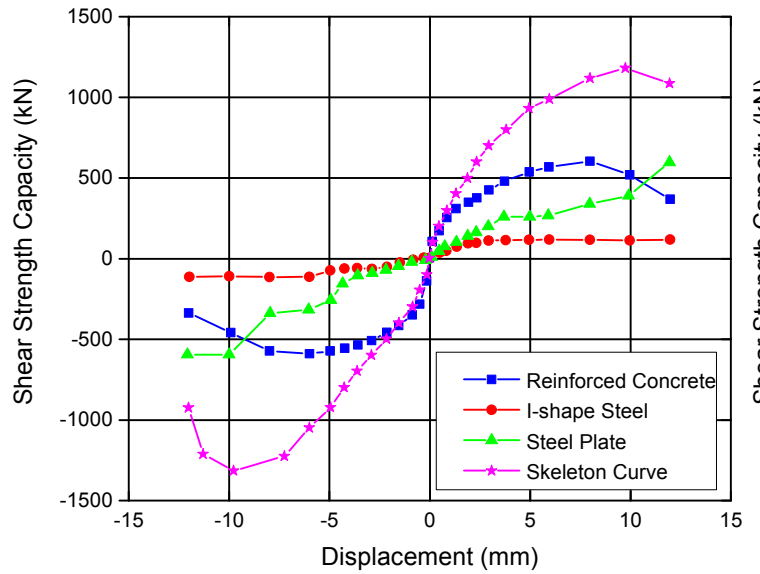

(a) RCSPSW 1-2 Specimen

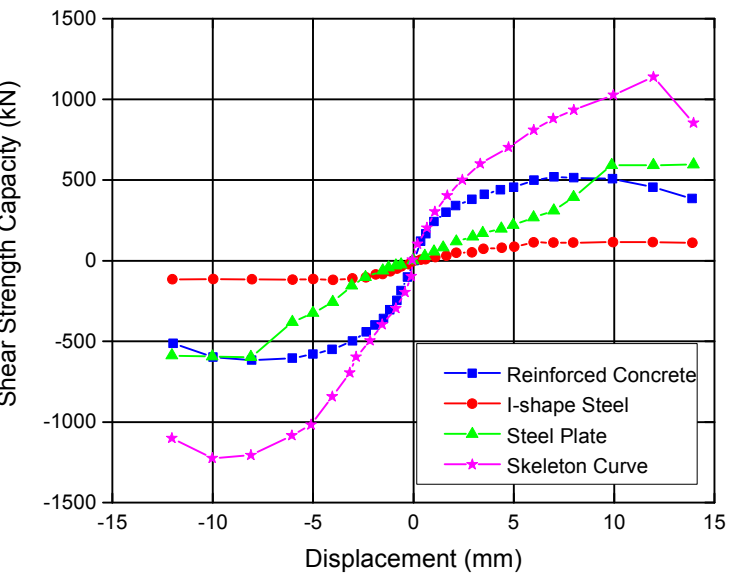

(b) RCSPSW 1-3 Specimen

Figure 18. Shear Strength Capacities of RCSPSW Specimens Provided by Different Components.

\subsection{Flexural Strength Model}

The strain gauges were attached on the bottom part of the embedded steel plate in flexure specimens, as shown in Figure $4 \mathrm{~b}$. Figure 19a presents the measured strain distribution along the wall depth at the peak point. It is observed that the strain distribution keeps close to a linear fashion when the specimen reaches the peak lateral load capacity. Under such circumstance, the design flexure strength model is established based on the plain section assumption and the form refers to the bearing capacity equations of eccentrically-compressed members in Chinese Code for Design of Composite Structures [50], as represented in Figure 19b and given in Equation (8):

$$
\left\{\begin{array}{c}
N \leq N_{\mathrm{c}}+f_{\mathrm{a}}^{\prime} A_{\mathrm{a}}^{\prime}+f_{\mathrm{y}}^{\prime} A_{\mathrm{s}}^{\prime}-\sigma_{\mathrm{a}} A_{\mathrm{a}}-\sigma_{\mathrm{s}} A_{\mathrm{s}}+N_{\mathrm{sw}}+N_{\mathrm{pw}} \\
N\left(e_{0}+\frac{h}{2}-a\right) \leq M_{\mathrm{c}}+f_{\mathrm{a}}^{\prime} A_{\mathrm{a}}^{\prime}\left(h_{0}-a_{\mathrm{a}}^{\prime}\right)+f_{\mathrm{y}}^{\prime} A_{\mathrm{s}}^{\prime}\left(h_{0}-a_{\mathrm{s}}^{\prime}\right)+M_{\mathrm{sw}}+M_{\mathrm{pw}} \\
M=N e_{0} \\
V_{f}=\frac{M}{H}
\end{array}\right.
$$

where $M$ and $N$ are the design moment and axial force values; $V_{f}$ is the design shear strength; $e_{0}$ is the eccentricity of the axial compression force; $H$ is the shear wall height; $h$ is the depth of wall section; $a$ is the distance from the extreme tension fiber to centroid of resultant tensile force in tensile I-shape steels and steel reinforcement; $h_{0}$ is the effective depth of wall section; $f_{\mathrm{a}}^{\prime}$ and $f_{\mathrm{y}}^{\prime}$ are the yield strength of compressive I-shape steels and steel reinforcement; $A_{\mathrm{a}}^{\prime}$ and $A_{\mathrm{y}}^{\prime}$ are the areas of compressive I-shape steels and steel reinforcement; $\sigma_{\mathrm{a}}$ and $\sigma_{\mathrm{s}}$ are stresses of tensile I-shape steels and steel reinforcement; $A_{\mathrm{a}}$ and $A_{\mathrm{s}}$ are areas of tensile I-shape steels and steel reinforcement; and, $a_{\mathrm{a}}^{\prime}$ and $a_{\mathrm{s}}^{\prime}$ are distances from the extreme compression fiber to centroid of resultant compressive force in tensile I-shape steels and steel reinforcement. $M_{\mathrm{c}}, M_{\mathrm{sw}}$, and $M_{\mathrm{pw}}$ are the design moment values provided by concrete section, longitudinal steel reinforcement distributed in the wall web, and embedded steel plate, and $N_{c}, N_{s w}$, and $N_{p w}$ are the design axial force values that are provided by those three components concrete section, which can be determined by Equations (9)-(12): 
when $x \geq h_{\mathrm{f}}^{\prime}$

$$
\left\{\begin{array}{l}
N_{\mathrm{c}}=\alpha_{1} f_{\mathrm{c}}\left[\xi b_{\mathrm{w}} h_{0}+\left(b_{\mathrm{f}}^{\prime}-b_{\mathrm{w}}\right) h_{\mathrm{f}}^{\prime}\right] \\
M_{\mathrm{c}} \leq \alpha_{1} f_{\mathrm{c}}\left[\xi(1-0.5 \xi) b_{w} h_{0}^{2}+\left(b_{\mathrm{f}}^{\prime}-b_{\mathrm{w}}\right) h_{\mathrm{f}}^{\prime}\left(h_{0}-0.5 h_{\mathrm{f}}^{\prime}\right)\right]
\end{array}\right.
$$

when $x<h_{\mathrm{f}}^{\prime}$

$$
\left\{\begin{array}{l}
N_{\mathrm{c}}=\alpha_{1} f_{\mathrm{c}} \xi b_{\mathrm{f}}^{\prime} h_{0} \\
M_{\mathrm{c}} \leq \alpha_{1} f_{\mathrm{c}} \xi(1-0.5 \xi) b_{\mathrm{f}}^{\prime} h_{0}^{2}
\end{array}\right.
$$

when $x \leq \beta_{1} h_{0}$

$$
\left\{\begin{array}{l}
N_{s w}=\left(1+\frac{x-\beta_{1} h_{0}}{0.5 \beta_{1} h_{5 w}}\right) f_{y w} A_{s w} \\
N_{\mathrm{pw}}=\left(1+\frac{x-\beta_{1} h_{0}}{0.5 \beta_{1} h_{\mathrm{pw}}}\right) f_{\mathrm{pw}} A_{\mathrm{pw}} \\
M_{s w}=\left[0.5-\left(\frac{x-\beta_{1} h_{0}}{\beta_{1} h_{\mathrm{sw}}}\right)^{2}\right] f_{y w} A_{s w} h_{s w} \\
M_{\mathrm{pw}}=\left[0.5-\left(\frac{x-\beta_{1} h_{0}}{\beta_{1} h_{\mathrm{pw}}}\right)^{2}\right] f_{\mathrm{pw}} A_{\mathrm{pw}} h_{\mathrm{pw}}
\end{array}\right.
$$

when $x>\beta_{1} h_{0}$

$$
\left\{\begin{array}{l}
N_{\mathrm{sw}}=f_{\mathrm{yw}} A_{\mathrm{sw}} \\
N_{\mathrm{pw}}=f_{\mathrm{p}} A_{\mathrm{p}} \\
M_{\mathrm{sw}}=0.5 f_{\mathrm{yw}} A_{\mathrm{sw}} h_{\mathrm{sw}} \\
M_{\mathrm{pw}}=0.5 f_{\mathrm{pw}} A_{\mathrm{pw}} h_{\mathrm{pw}}
\end{array}\right.
$$

where $x$ is the depth of the compression zone, and $\xi=x / h_{0} ; \alpha_{1}$ is the concrete stress block factor that is related to equivalent rectangular concrete compressive stress block intensity; $f_{\mathrm{c}}$ is the concrete compressive strength; $b_{\mathrm{f}}^{\prime}$ and $b_{\mathrm{w}}$ are the width of wall flange and web; $h_{\mathrm{f}}^{\prime}$ is the depth of wall flange; $\beta_{1}$ is the stress block factor that is related to concrete strength; $h_{\mathrm{sw}}$ and $h_{\mathrm{pw}}$ are the depth of distributed longitudinal reinforcement and embedded steel plate in concrete web; $f_{\mathrm{yw}}$ and $f_{\mathrm{pw}}$ are the yield strength of distributed longitudinal reinforcement and embedded steel plate; and, $A_{\mathrm{sw}}$ and $A_{\mathrm{pw}}$ are the areas of distributed longitudinal reinforcement and embedded steel plate.

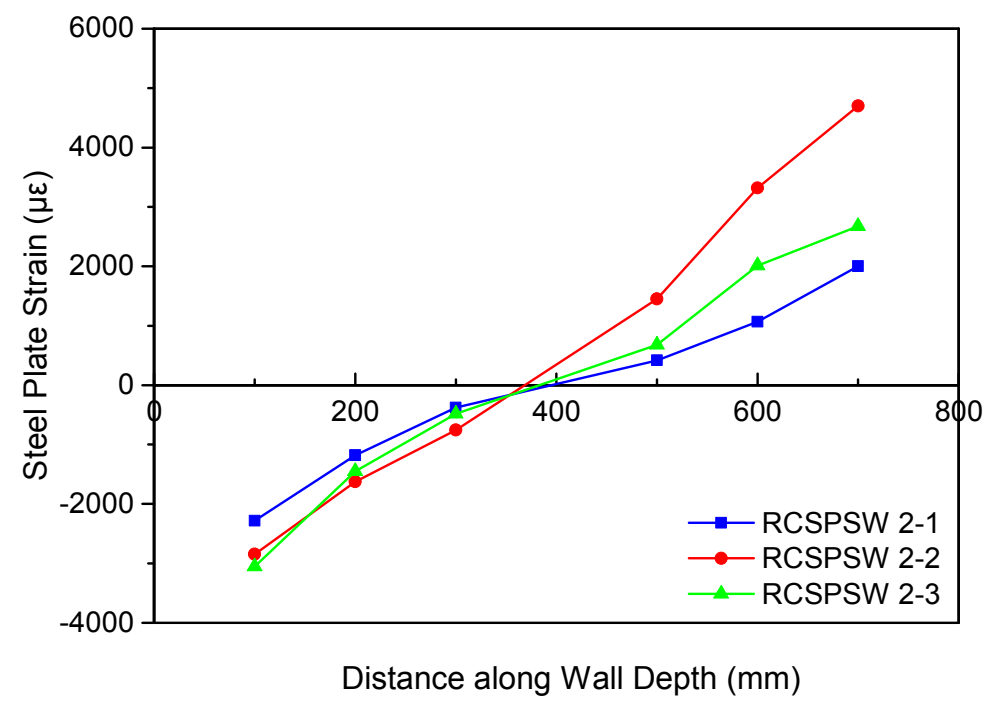

(a) Strain Distribution along Wall Depth

Figure 19. Cont. 


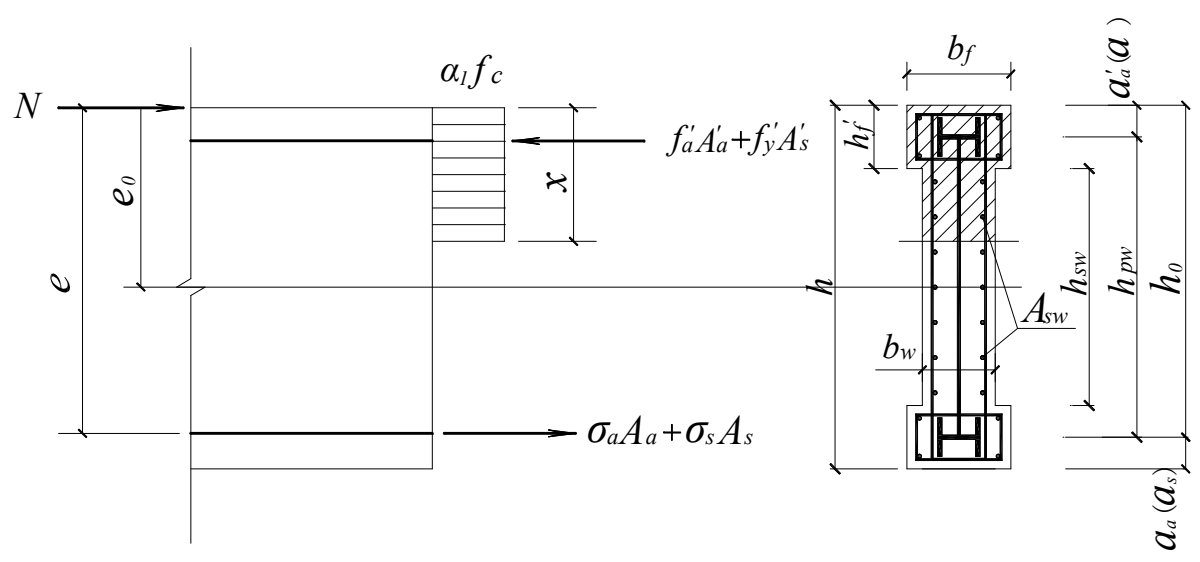

(b) Flexure Design Models and Notations

Figure 19. Flexure Design Models Developed based on Plane Section Assumption.

Table 8 summarizes the flexure strength capacities measured from the quasi-static cyclic load test and calculated by flexure strength models. It is seen that the flexure strength capacities predicted by the design models are approximately 20-35 percent lower than the measured values in both positive and negative directions. Similar with the shear model, a correction factor, $k_{f}$, of 1.1 is added to achieve a reasonable degree of conservatism. Figure $16 \mathrm{~b}$ compares the design strength capacities with experimental values for flexure specimens, in which the line and symbol types are the same with Figure 16a. It is observed that the modified design flexure capacities are generally 10-20 percent as compared to the test values, verifying the reliability of the suggested design models.

Table 8. Comparisons of Experimental and Design Strength Capacities for Flexure Specimens.

\begin{tabular}{|c|c|c|c|c|c|c|c|}
\hline \multirow{2}{*}{ Specimen No. } & \multicolumn{3}{|c|}{ Experimental Results (kN) } & \multirow{2}{*}{$\begin{array}{l}\text { Design Model } \\
\text { Results (kN) }\end{array}$} & \multicolumn{3}{|c|}{ Differences } \\
\hline & Positive & Negative & Average & & Positive & Negative & Average \\
\hline RCSW 2-1 & 469 & 514 & 492 & 341 & $27 \%$ & $34 \%$ & $30 \%$ \\
\hline RCSW 2-2 & 540 & 536 & 538 & 389 & $28 \%$ & $27 \%$ & $28 \%$ \\
\hline RCSW 2-3 & 570 & 578 & 574 & 481 & $16 \%$ & $17 \%$ & $16 \%$ \\
\hline RCSPSW 2-1 & 581 & 697 & 639 & 387 & $33 \%$ & $44 \%$ & $39 \%$ \\
\hline RCSPSW 2-2 & 646 & 674 & 660 & 434 & $33 \%$ & $36 \%$ & $34 \%$ \\
\hline RCSPSW 2-3 & 674 & 701 & 688 & 512 & $24 \%$ & $27 \%$ & $25 \%$ \\
\hline
\end{tabular}

\section{Summary and Conclusions}

This paper introduces a high-strength reinforced concrete-steel plate composite shear wall system as lateral load resisting elements the design of high-rise building structures. A total of 11 RCSW and RCSPSW specimens were tested under quasi-static cyclic lateral loading to investigate the effects of critical factors on their seismic performances, including embedment of steel plate, aspect ratio, axial compression ratio, etc. Throughout the test procedure, the progression of damage and failure modes were observed and the key parameters were determined, such as lateral load capacity, ultimate displacement, ductility factor, and EVD coefficient. In addition, the design models were suggested to determine the shear and flexure strength of RCSPSW. By analyzing the data collected from experimental tests, the following conclusions are drawn.

1. Shear and flexure modes of failure dominate in specimens with the aspect ratio of 1.5 and 2.7 , respectively. Inclined cracks were observed on the shear specimens, whilst flexure-tension cracks and flexure-shear cracks were mainly distributed in the lower half of boundary elements and wall web in flexure specimens. As compared to the RCSW specimens, more densely-distributed, 
but finer, cracks took place in the RCSPSW specimens. With the increase of axial compressive loads, the crack quantity becomes less and the crack width is smaller due to the compaction of compression forces.

2. Obvious pinching" effects were observed in hysteresis loops of RCSW specimens. With the embedment of the steel plate, hysteresis curves appear in a plumper shape with higher peak lateral load capacities, but a severer post-peak strength and stiffness degradation.

3. RCSPSW system demonstrates superior lateral load capacities over RCSW, in general. The RCSPSW shear specimens show acceptable deformability for design purpose with the ultimate drift value of $1.0 \%$. As for RCSPSW flexure specimens, the ultimate drift is larger than $1.0 \%$ and the ductility factor is around 4 when the axial compression ratio is lower than 0.50 .

4. Axial compression ratio has an indispensable effect on the lateral load performance of wall specimens. In general, the peak lateral load increases, but ultimate displacement decreases as the axial compression ratio increases. A severer strength and stiffness degradation was observed for RCSPSW flexure specimens with the axial compression ratio higher than 0.50 . When the axial compression ratio increases to 0.58 , the ductility factor substantially decreased to 2.61 and the ultimate drift is lower than $1.0 \%$.

5. The brittleness of high-strength concrete explains the relatively lower deformability of the RCSPSW specimens under high axial compression ratios. Another possibility is the weak concrete confinement effect on the embedded steel plate due to the small wall thickness values of the test specimens. The steel plate tends to buckle when severe concrete spalling occurs under higher axial compressive loads, causing substantial strength and stiffness degradation.

6. Energy dissipation capacities found in shear mode of failure are generally weaker than those in flexure-controlled failure, and the embedment of steel plate effectively improves the energy dissipation ability of RCSW.

7. The suggested design models generally provide conservative design values for shear and flexure strength of RCSPSW. A reasonable degree of conservatism is obtained by using correction factors: $k_{s}=0.9$ and $k_{f},=1.1$.

8. Shear walls are suggested to be designed with caution when subjected to high axial compressive loads and an upper limit of axial compression ratio (0.5) should be set for RCSPSW that is based on experimental observations. Steel ties or shear studs should be used to strengthen the connection between the steel plate and concrete on both sides for detailing in high-strength RCSPSW system. Besides, a higher transverse reinforcement ratio is recommended to further improve the concrete confinement effect.

Author Contributions: Conceptualization, D.J. and C.X.; methodology, D.J., C.X. and T.C.; validation, Y.Z.; formal analysis, D.J. and T.C.; investigation, D.J.; C.X. and T.C.; writing-original draft preparation, D.J.; writing-review and editing, C.X. and T.C.; supervision, C.X.; project administration, D.J.; funding acquisition, D.J.

Funding: This project was supported by Natural Science Foundation of Jiangsu Province under Grant No. BK20180487, National Natural Science Foundation of China (NSFC) under Grant Nos. 51808292 and 51508276, and Nanjing University of Science and Technology Start-up Grant AE89958.

Acknowledgments: The authors are grateful to collaborators from China Academy of Building Research (CABR) who provided invaluable assistance in the experimental test of high-strength concrete-steel plate composite shear walls.

Conflicts of Interest: The authors declare no conflict of interest. The funders had no role in the design of the study; in the collection, analyses, or interpretation of data; in the writing of the manuscript, or in the decision to publish the results.

\section{References}

1. Luna, B.N.; Rivera, J.P.; Whittaker, A. Seismic behavior of low-aspect-ratio reinforced concrete shear walls. ACI Struct. J. 2015, 112, 593-605. [CrossRef]

2. Taranath, B.S. Reinforced Concrete Design of Tall Buildings; CRC Press: Boca Raton, FL, USA, 2009. 
3. Chinese Building Standard Committee. National Standard of the People's Republic of China: Technical Specification for Concrete Structures of Tall Building (JGJ 3-2010); China Architecture \& Building Press: Beijing, China, 2010.

4. American Concrete Institute (ACI). Building Code Requirements for Structural Concrete (ACI 318-14) and Commentary; ACI: Farmington Hills, MI, USA, 2014; p. 520.

5. Salonikios, T.N. Shear strength and deformation patterns of R/C walls with aspect ratio 1.0 and 1.5 designed to eurocode 8 (EC8). Eng. Struct. 2002, 24, 39-49. [CrossRef]

6. Lopes, M. Experimental shear-dominated response of RC walls Part I: Objectives, methodology and results. Eng. Struct. 2001, 23, 229-239. [CrossRef]

7. Tasnimi, A. Strength and deformation of mid-rise shear walls under load reversal. Eng. Struct. 2000, 22, 311-322. [CrossRef]

8. Zhang, Y.; Wang, Z. Seismic Behavior of Reinforced Concrete Shear Walls Subjected to High Axial Loading. ACI Struct. J. 2000, 97, 739-750.

9. Su, R.K.L.; Wong, S.M. Seismic behaviour of slender reinforced concrete shear walls under high axial load ratio. Eng. Struct. 2007, 29, 1957-1965. [CrossRef]

10. Moradi, M.J.; Hariri-Ardebili, M.A. Developing a Library of Shear Walls Database and the Neural Network Based Predictive Meta-Model. Appl. Sci. 2019, 9, 2562. [CrossRef]

11. Dan, D.; Fabian, A.; Stoian, V. Theoretical and experimental study on composite steel-concrete shear walls with vertical steel encased profiles. J. Constr. Steel Res. 2011, 67, 800-813. [CrossRef]

12. Tong, X.; Hajjar, J.F.; Schultz, A.E.; Shield, C.K. Cyclic behavior of steel frame structures with composite reinforced concrete infill walls and partially-restrained connections. J. Constr. Steel Res. 2005, 61, 531-552. [CrossRef]

13. Hajjar, J.F. Composite steel and concrete structural systems for seismic engineering. J. Constr. Steel Res. 2002, 58, 703-723. [CrossRef]

14. Liao, F.-Y.; Han, L.-H.; Tao, Z. Seismic behaviour of circular CFST columns and RC shear wall mixed structures: Experiments. J. Constr. Steel Res. 2009, 65, 1582-1596. [CrossRef]

15. Qian, J.; JIang, Z.; Ji, X. Experimental study on seismic behavior of steel tube-reinforced concrete composite shear walls with high axial compressive load ratio. J. Build. Struct. 2010, 31, 40-48.

16. Cao, W.; Wang, M.; Wang, S.; Zhang, J.; Zeng, B. A seismic research of composite shear wall and core walls with rectangular concrete filled steel tube columns. Eng. Mech. 2008, 25, 58-70.

17. Cho, S.H.; Tupper, B.; Cook, W.D.; Mitchell, D. Structural Steel Boundary Elements for Ductile Concrete Walls. ASCE J. Struct. Eng. 2004, 130, 762-768. [CrossRef]

18. Esaki, F.; Ono, M. Effect of loading rate on mechanical behavior of SRC shearwalls. Steel Compos. Struct. 2001, 1, 201-212. [CrossRef]

19. Zhou, Y.; Lu, X.; Dongq, Y. Seismic behavior of composite shear walls with multi-embedded steel sections. Part I: Experiment. Struct. Des. Tall Spec. Build. 2010, 19, 637-655. [CrossRef]

20. Hu, H.-S.; Nie, J.-G.; Eatherton, M.R. Deformation capacity of concrete-filled steel plate composite shear walls. J. Constr. Steel Res. 2014, 103, 148-158. [CrossRef]

21. Nie, J.-G.; Ma, X.-W.; Tao, M.-X.; Fan, J.-S.; Bu, F.-M. Effective stiffness of composite shear wall with double plates and filled concrete. J. Constr. Steel Res. 2014, 99, 140-148. [CrossRef]

22. Hossain, K.M.A.; Wright, H.D. Experimental and theoretical behaviour of composite walling under in-plane shear. J. Constr. Steel Res. 2004, 60, 59-83. [CrossRef]

23. Rafiei, S.; Hossain, K.M.A.; Lachemi, M.; Behdinan, K.; Anwar, M.S. Finite element modeling of double skin profiled composite shear wall system under in-plane loadings. Eng. Struct. 2013, 56, 46-57. [CrossRef]

24. Zhao, Q.; Astaneh-Asl, A. Cyclic Behavior of Traditional and Innovative Composite Shear Walls. ASCE J. Struct. Eng. 2004, 130, 271-284. [CrossRef]

25. American Institute of Steel Construction (AISC). Seismic Provisions for Structural Steel Buildings (ANSI/AISC 341-10); AISC: Chicage, IL, USA, 2010.

26. Sun, J.; Xu, P.; Xiao, C.; Sun, H.; Wang, C. Experimental study on shear behavior of steel plate-concrete composite wall. Build. Struct. 2008, 38, 6-10.

27. Chen, T.; Xiao, C.; Tian, C.; Xu, P. Experimental study of the compression-bending behavior of composite shear walls of high axial compression ratio. China Civ. Eng. J. 2011, 44, 9-15.

28. Xiao, C.; Jiang, D.; Xu, Z.; Chen, T. Seismic behavior of steel plate reinforced concrete shear walls. In Proceedings of the 9th CTBUH World Congress, Shanghai, China, 19-21 September 2012; pp. 671-678. 
29. Lu, X.; Jiang, H. Recent progress of seismic research on tall buildings in China Mainland. Earthq. Eng. Eng. Vib. 2014, 13, 47-61. [CrossRef]

30. Jiang, D.; Xiao, C.; Chen, T.; Tian, C.; Xu, P. Experimental study of the compression-bending behavior of high-strength concrete steel composite shear walls. China Civ. Eng. J. 2012, 45, 17-25.

31. Xiao, C.; Tian, C.; Chen, T.; Jiang, D. Compression-bending behavior of steel plate reinforced concrete shear walls with high axial compression ratio. In Proceedings of the 15th World Conference on Earthquake Engineering, Lisbon, Portugal, 24-28 September 2012.

32. Olivari, C.N.A. Influence of Axial load in the Seismic Behavior of Reinforced Concrete Walls with Nonseismic Detailing. Master's Thesis, Pontificia Universidad Católica de Chile, Santiago, Chile, 2013; p. 108.

33. Greifenhagen, C.; Lestuzzi, P. Static cyclic tests on lightly reinforced concrete shear walls. Eng. Struct. 2005, 27, 1703-1712. [CrossRef]

34. Hidalgo, P.A.; Ledezma, C.A.; Jordan, R.M. Seismic behavior of squat reinforced concrete shear walls. Earthq. Spectra 2002, 18, 287-308. [CrossRef]

35. Takahashi, S.; Yoshida, K.; Ichinose, T.; Sanada, Y.; Matsumoto, K.; Fukuyama, H.; Suwada, H. Flexural Drift Capacity of Reinforced Concrete Wall with Limited Confinement. ACI Struct. J. 2013, 110, 95-104.

36. Chinese Building Standard Committee. National Standard of the People's Republic of China: Specification for Seismic Test of Buildings (JGJ/T 101-2015); China Architecture \& Building Press: Beijing, China, 2015.

37. Liao, F.Y.; Han, L.H.; Tao, Z. Performance of reinforced concrete shear walls with steel reinforced concrete boundary columns. Engineering Structures. 2012, 44, 186-209. [CrossRef]

38. Priestley, M.J.N.; Park, R. Strength and ductility of concrete bridge columns under seismic loading. ACI Struct. J. 1987, 84, 61-76.

39. Mahin, S.A.; Bertero, V.V. Problems in establishing and predicting ductility in aseismic design. In Proceedings of the International Symposium on Earthquake Structural Engineering, University of Missouri, Rolla, MO, USA, 19-21 August 1976; pp. 613-628.

40. American Society for Testing and Materials (ASTM). Standard test methods for cyclic (reversed) load test for shear resistance of vertical elements of the lateral force resisting systems for buildings. In ASTM E2126; ASTM: West Conshohocken, PA, USA, 2011.

41. Park, R. Ductility evaluation from laboratory and analytical testing. In Proceedings of the 9th World Conference on Earthquake Engineering, Tokyo-Kyoto, Japan, 2-9 August 1988; pp. 605-616.

42. Chopra, A.K. Dynamics of Structures: Theory and Applications to Earthquake Engineering; Prentice-Hall: Upper Saddle River, NJ, USA, 2011.

43. Hariri-Ardebili, M.A.; Saouma, V.E. Sensitivity and uncertainty analysis of AAR affected reinforced concrete shear walls. Eng. Struct. 2018, 172, 334-345. [CrossRef]

44. Dancygier, A.N.; Katz, A. Bond over direct support of deformed rebars in normal and high strength concrete with and without fibers. Mater. Struct. 2012, 45, 265-275. [CrossRef]

45. Harajli, M.H.; Gharzeddine, O. Effect of steel fibers on bond performance of steel bars in NSC and HSC under load reversals. J. Mater. Civ. Eng. 2007, 19, 864-873. [CrossRef]

46. Gattesco, N.; Amadio, C.; Bedon, C. Experimental and numerical study on the shear behavior of stone masonry walls strengthened with GFRP reinforced mortar coating and steel-cord reinforced repointing. Eng. Struct. 2015, 90, 143-157. [CrossRef]

47. Smarzewski, P. Analysis of Failure Mechanics in Hybrid Fibre-Reinforced High-Performance Concrete Deep Beams with and without Openings. Materials 2018, 12, 101. [CrossRef]

48. Pan, A.; Moehle, J.P. Lateral displacement ductility of reinforced concrete flat plates. ACI Struct. J. 1989, 86, 250-258.

49. Lim, W.-Y.; Hong, S.-G. Shear tests for ultra-high performance fiber reinforced concrete (UHPFRC) beams with shear reinforcement. Int. J. Concr. Struct. Mater. 2016, 10, 177-188. [CrossRef]

50. Chinese Building Standard Committee. National Standard of the People's Republic of China: Code for Design of Composite Structures (JGJ 138-2016); China Architecture \& Building Press: Beijing, China, 2016.

(C) 2019 by the authors. Licensee MDPI, Basel, Switzerland. This article is an open access article distributed under the terms and conditions of the Creative Commons Attribution (CC BY) license (http://creativecommons.org/licenses/by/4.0/). 